\title{
The use of QCA in science, technology and innovation studies: a review of the literature and an empirical application to knowledge transfer
}

\author{
Manuel Fernández-Esquinas 1,3 - María Isabel Sánchez-Rodríguez ${ }^{2,3}$. \\ José Antonio Pedraza-Rodríguez ${ }^{2,3} \cdot$ Rocío Muñoz-Benito ${ }^{2,3}$
}

Received: 17 December 2019 / Accepted: 22 April 2021 / Published online: 23 June 2021

(c) The Author(s) 2021

\begin{abstract}
This article analyses the use of qualitative comparative analysis (QCA) in social studies on science, technology and innovation. The goals are to address how and why the method is used, and to explore the advantages and shortcomings for this research area. A review of the literature and practical application are combined. Firstly, the article finds that the acceptance of QCA is unevenly distributed in the major research fields related to knowledge production. It is used mainly to study innovation in firms but is largely absent in science and technology studies. Second, an original study on university-industry links provides a strategic site that displays how research unfolds. Its findings demonstrate the combinations of factors that shape knowledge transfer and the configurational nature of the process. The article offers an account of challenges and directions for future research and discusses the possibilities of the method as a third way between qualitative and quantitative traditions in science, technology and innovation.
\end{abstract}

Keywords QCA · Science · Technology · Innovation · Knowledge transfer · Universities · SMEs local innovation systems

\section{Introduction}

There has been a marked division between qualitative and quantitative approaches in social studies on science and technology (Leydesdorff, 1989). Despite sharing a common origin, the major research fields ${ }^{1}$ in this domain have been championed by scientific

\footnotetext{
${ }^{1}$ We use the term research fields to refer to distinctive research communities in the wider research area of science, technology and innovation and its different domains. Research fields are characterized by preferential objects of study, methodologies and a shared knowledge base. They are usually identified with leading

Manuel Fernández-Esquinas

mfernandez@iesa.csic.es

1 Institute for Advanced Social Studies-CSIC, Cordoba, Spain

2 Statistics and Business Department, University of Cordoba, Cordoba, Spain

3 Joint Research Unit On "Innovation and Knowledge Transfer", CSIC/University of Cordoba, Cordoba, Spain
} 
communities with different epistemological and methodological orientations. On the one hand, the research field of Science and Technology Studies (STS) has preferred to observe knowledge-building processes through interpretative analyses. Scholars in this field often concentrate on phenomena which enable the application of reflexive strategies to observe meanings, interests and social processes in the construction of science and technology (Edge, 1995; Martin et al., 2012). They are therefore more favoured for qualitative observations of a narrative nature, usually in micro-level situations, to a greater extent than structured data sources and statistical surveys. On the other hand, the more transversal research field of Science Policy and Innovation Studies (SPIS) is more interested in knowledge production and application with a practical orientation towards policy and management. This field shows a greater variety of methodological approaches, despite the presence of a marked division between quantitative and qualitative approaches (Fabergerg et al., 2013). Quantitative studies on science and technology as a distinctive research field (including bibliometrics) are usually closer to the latter in methodological issues and practical aims. They tend to focus on issues of production and organization of knowledge (Martin et al., 2012). They privilege macro and meso-levels of analysis. They use indicators to examine the formal and semantic aspects of scientific literature (van Raan, 1988), and numerical data from censuses, large-scale surveys, organizational data sources and, more recently, the analysis and visualization of Big Data from the digital world (Borgman, 2015).

The methodological division is largely due to both the technical possibilities of observation offered by some objects of study and the meta-theoretical assumptions in which epistemic communities have been socialized (Knorr-Cetina, 1999): the more constructivist and reflexive tradition versus the more realist and positivistic tradition. To bridge this gap, some scholars increasingly recommend combining approaches, sources and techniques. For instance, Wyatt et al. (2015) have argued for the use of bibliometrics in areas of problems typically addressed by STS. In the other direction there are also notabsle examples of qualitative methods that enhance typically quantitative approaches and the combination of methodologies (Venturini et al., 2015). Although triangulation strategies represent a more comprehensive alternative, there are few available techniques of a hybrid nature. Qualitative Comparative Analysis (QCA) is one of them.

For several reasons QCA is considered an approach that helps bridge the division when difficult phenomena are being studied. This methodology facilitates the analysis of small samples that do not acquire representativeness, or of relationships that do not adapt to statistical models. The capture of large units of analysis for which traditional variables are not available is also possible (Ragin, 1987). In addition, it offers an alternative treatment for some data sets that have traditionally been analyzed with statistical techniques only. Given its versatility, it is a suitable option for middle-range theoretical strategies in order to connect contextual realities with causal explanations that go beyond observations of specific cases (Wyatt \& Balmer, 2007). QCA has been commonly used in sociology and political science in a variety of settings, and lately in business, management and organization studies. QCA can also be used as a strategic methodology to combat the customary division between qualitative and quantitative traditions in the broader area of science, technology and innovation (STI hereinafter). Although it has often been applied to innovation issues in firms, few articles have been published in the specialized literature of science

Footnote 1 (continued)

journals (Whitley, 2000). As a convention, we use the term research domains in a broader sense to refer to the areas of interest related to science, technology and innovation. 
and technology on other topics and establishments. Therefore the role of QCA in studies focused on knowledge production, distribution and application has yet to be explored.

The goals of this article are twofold. First, through a review of the literature, we aim to map the use of QCA in different domains of science, technology and innovation, as well as its potential and limitations. Second, we aim to explore the application of the method in a particularly illustrative sector: university-industry knowledge transfer in local innovation systems. This empirical study has been chosen because it contains attributes that are relevant for our goals: namely the scarcity of indicators at a local level, the difficulties in carrying out representative surveys, the complexity of the processes that take place between organizations, and the distributional nature of the outcomes. The article also makes two types of contribution. First, we found that the use of this methodology is shaped by the intellectual composition of the different research fields. It is accepted in the field of innovation business management, but seldom in others. Studies in the domain of firms show its potential to capture the role of innovation in organizational performance and territorial innovation systems. These results provide some insights for studying other processes and activities in science and technology. In particular, how a strategic selection of cases makes it possible to construct dimensions similar to indicators, carry out analyses based on hypotheses and therefore facilitate a dialogue with more narrative strategies. Second, the empirical study itself provides a contribution. Using QCA enables us to observe the existence of knowledge transfer processes between SMEs and the university in unfavourable environments. Knowledge transfer is achieved by the types of activities developed and the relationships maintained with university agents. The results show the importance of the notion of configuration when knowledge transfer is studied. That is, a specific constellation of interconnected elements forms a mix leading to a given outcome. These findings are used to inform research designs and policy implications in other domains.

After this introduction, the article is divided into the following sections. Section Background: what QCA is and why it is important for science, technology and innovation studies outlines the features of QCA and explains its main areas of application. Section Literature review: an exploration of the use of QCA in science, technology and innovation studies provides a literature review supported by a bibliometric exploration. Section An empirical application: the study of university-industry relationships in innovation systems is dedicated to its application to the relationships between universities and firms in local innovation systems. The section specifies the research site and the steps taken when this technique is used, including observations, hypotheses and coding process. Section Analysis and results focuses on the results of the empirical study. Section Discussion: some challenges and directions for future research discusses the main research problems when using QCA and the issues for a research agenda in STI domains. The conclusions highlight the implications of the findings.

\section{Background: what QCA is and why it is important for science, technology and innovation studies}

Developed originally in the area of comparative political science and historical sociology (Ragin, 1987), QCA is a research technique that emerges at the intersection of two typical methodological problems in the social sciences: the representativeness of small samples and the qualitative-quantitative divide. Unlike quantitative analysis, which is based on a significantly high number of cases, and qualitative analysis based on direct observations 
Table 1 Phases in QCA

\begin{tabular}{ll}
\hline Phase & Description \\
\hline 0 & \\
1 & $\begin{array}{l}\text { Formulation of hypothesis based on defined dimensions. Theoretical selection of cases } \\
\text { Definition of conditions and outcomes. Calibration: dichotomization* or } \text { grada- } \\
\text { tion** against a defined standard }\end{array}$ \\
& Analysis of necessity: determining consistency -supersets of the outcome \\
3 & Analysis of sufficiency (a): determining coverage-subsets of the outcome \\
4 & Analysis of sufficiency (b): building truth tables \\
5 & Analysis of sufficiency (c): finding solutions \\
6 & Interpreting results. Verifying hypotheses
\end{tabular}

* Procedures of Boolean algebra. ** Procedures of Fuzzy-set theory

and interpretations of complex facts, QCA enables a small number of case studies to be used simultaneously through a procedure of explanatory analysis susceptible to formalization, making it easy to implement through software. However, it is important to note that many scholars specializing in the method highlight the fact that QCA is a research approach grounded in a substantive epistemology rather than just a computer-based data analysis (Schneider \& Wagemann, 2010).

An initial feature that distinguishes QCA from statistical methods is that it takes a case $^{2}$ rather than a variable perspective in the analysis. It changes the focus of investigation from the individual unit of analysis to the different configurations of actors and contextual characteristics that together are responsible for the outcome of interest (Rihoux \& Marx, 2013). The selection of cases according to strategic decisions and hypothesis about causality, instead of statistical representativeness, together with the comparative rationale, is a fundamental feature of the methodology. A second characteristic is related to measurement (or calibration). Objects of varying degrees of complexity can be examined using classification procedures prior to the construction of a dimension that resembles the nature of a variable, although measurement is based on specific assumptions. Hence variables are usually called dimensions. Calibration allows for classifications adapted to concepts that are difficult to transform directly into quantifiable dimensions and that can be adapted according to the sets of cases under investigation. For example, it is suitable for large units of analysis, such as programmes, complex organizations and territorial units, where discrete measurements for dimensions important for research are difficult to come by. Classifications are based on meaningful observations that can be identified as attributes of the units of analysis observed against the concepts of departure.

A third characteristic is that QCA develops a conception of causality that makes room for complexity arising from multiple configurations. A configuration is defined as a constellation of interconnected elements that may incorporate some systemic attributes (Fiss et al., 2013). It is predicated on the assumption that different combinations of factors might lead to the same outcome instead of a linear additive model. It aims to identify configurations of social and contextual characteristics that may be associated with a given outcome. Analysing cases in these terms facilitates the identification of necessary and sufficient

$\overline{2}$ Italics are used to identify the basic vocabulary of QCA. The terms are highlighted in Table 1. 
conditions for the outcome to be obtained. Therefore, it appears not to suffer from some of the limitations of the statistical methods often used in causal analysis (Rihoux et al., 2013). Its origin lies in Boolean logic and more recently in fuzzy-set theory. QCA and traditional statistical techniques share the objective of determining causality relationships between variables or dimensions. However, QCA explores how combinations of conditions form the pathways to a certain outcome, instead of analysing the individual impact of independent variables on dependent ones. It has been suggested that this rationale of causality might correspond better to the epistemological bases of social science research than other ways of modelling complex social phenomena (Hall, 2003), even where large data sets are available.

Currently, there are three dominant techniques: crisp-set (csQCA), multi-value (mvQCA) and fuzzy-set (fsQCA), depending on whether the dimensions observed in the analysis are classified as dichotomous, multichotomous or fuzzy, respectively. The classification can stem from the nature of the dimensions being studied by the researcher on the basis of a justified threshold from a theoretical and empirical perspective. Dimensions look like independent and dependent variables in the sense that they try to capture a valid measure of an object that can be used in analysis as "explanans" and "explanandum". To that end, the conditions (equivalent to independent variables) and the outcomes (equivalent to dependent variables) are defined and coded. But instead of regular variables, they are better understood in terms of membership to a set of attributes. The criteria for membership are calibrated against an external standard that is theoretically constructed. When the nature of the object —or the information available to codify the data-is only suitable for a dichotomous classification, the use of coding in two discrete categories is recommended in the conditions and outcomes. Boolean procedures are therefore applied. Code [0] and code [1] represent the absence and presence of a characteristic, or non-membership versus membership to a set. When a gradation is justified, the use of fuzzy-set procedures is considered more accurate than dichotomous classifications. After careful examination of the object under study, classifications into categories are usually operationalized through a scale ranging from code [0] "completely outside the defined category", to code [5] "completely inside the defined category", although other gradations are possible. The methodology recommends gradation be justified through theoretical or empirical arguments in order to establish specific thresholds on a scale from which qualitative changes can be made (Rihoux et al., 2013).

Stages or phases are usually established in order to proceed systematically (Table 1 summarizes the main stages of implementation). Phase 0 has been included to highlight the importance of justifying case selection and formulating a general hypothesis regarding relationships between dimensions. In phase 1, the researcher defines the conditions and outcomes, grounded in previous hypotheses, and the calibration or measurement criteria that must be considered when coding (Ragin, 1987; Rihoux \& Marx, 2013). Causal relationships in QCA are deterministic, not probabilistic. Boolean algebra and set theory are based on ideas of necessity and sufficiency. A condition is necessary if each time the outcome is present, the condition is also present (in set theory, the condition is a superset of the result). That is, the outcome cannot be reached if the condition is not present. Moreover, a condition is sufficient for the outcome if each time it is present in the cases, the outcome is also present. The possible sets that represent necessary and/or sufficient conditions provide individual analysis of the conditions, as well as the logical combinations or configurations.

Phase 2 involves an analysis of necessity, which seeks to identify the supersets of the outcome. This is how consistency is calculated. Consistency refers to the likelihood of a 
configuration affecting the outcome, and expresses the percentage of cases that verify the condition divided by the cases in which the outcome of interest is present. Phase 3 includes sufficiency (technically sub-phases a, b and c) are considered different steps in sufficiency analysis; however, their importance means they are distinguished as logical phases). Step a) of the analysis refers to coverage. Coverage consists in the likelihood of the outcome of interest being conditioned by the configuration. Therefore, coverage expresses the percentage of cases that present the outcome of interest divided by the cases that verify the condition. In QCA it is interesting to identify high values for the consistency and coverage of the various conditions that represent the degree of necessity and sufficiency, respectively.

Phase 4 consists in the construction of the truth table. Unlike the descriptive data table (where each row refers to a case of observation), the rows in the truth table contain all possible configurations or combinations (though they may not have been empirically observed). Thus, if a descriptive table based on dichotomous classifications gives $k$ conditions, $2^{k}$ will be the number of rows in the truth table. Phase 5 entails obtaining solutions from a minimization process. That is, simplified combinations of conditions with the outcome of interest identified from the truth table. In the final phase, the solutions must be interpreted, resulting in the acceptance or refutation of the starting hypotheses. ${ }^{3}$

QCA is therefore a hybrid methodology that has certain advantages for research endeavours bordering on both qualitative and quantitative traditions (Rihoux et al., 2011). In terms of data sources, it can be applied to a diversity of settings and units of analysis. In terms of explanatory strategy, one advantage is that it focuses on the contrast of hypotheses, thereby facilitating the use of causal logic with narrative-like information that may initially appear fairly unsystematic. It therefore helps researchers to toggle between observations and previous hypotheses.

Since QCA appeared in the 1980s, it has been increasingly applied across different disciplines of the social sciences (Rihoux et al., 2013), mainly in comparative studies that cover a small number of cases in political science (Marcos-Marne, 2016; Meuer et al., 2015), international relations (Bennet and Elman, 2007), sociology and anthropology (Schulte, 2018; Warren, 2017), business and management (Adame et al., 2016; Pappas, 2017, 2018) and organizations in general (Cobo-Benita et al., 2016; Curado et al., 2018; Fan et al., 2016, 2017; Parida et al., 2017). In particular, an increasing number of scholars working with firms have been opting for multiple case studies as a research strategy. This choice is based on the need to gather in-depth insights into the various cases and to capture their complexity, while attempting to produce some level of generalization (Ragin, 1987), especially for exploring the most logical paths leading to organizational performance (Kraus et al., 2018).

Such a strategy is particularly relevant for science and technology-related research, since many relevant objects are limited in number and produce small-N or intermediate$\mathrm{N}$ study designs. To name a few: nation states or regions, research establishments, subunits such as university departments and laboratories, research programmes, projects and research groups. Some research products can be observed in detail only if a small number of cases are selected, such as the codification of outcomes incorporated in articles, patents and research applications. Moreover, in the domain of knowledge production it is sometimes difficult to proceed from assumptions about straightforward causal influences

\footnotetext{
${ }^{3}$ For an in-depth study of dichotomous QCA analysis, see Rihoux and Marx (2013). For an overview of software tools for set methods see Schneider and Wagamann (2012). Dusa (2019) provides a comprehensive guide to QCA using R-project.
} 
between variables. A distributional nature of the phenomena under study is often assumed. On occasion this strategy may also be applied to large samples. However, at present there is little information about the prospects of this methodology in the related research fields. The following section explores the state of research in the usual domains of science, technology and innovation studies.

\section{Literature review: an exploration of the use of QCA in science, technology and innovation studies}

\section{Scope of the literature review}

We have opted for a semi-systematic literature review procedure consisting in a bibliometric account followed by a narrative analysis of relevant publications (Snyder, 2015). We have based our search on the main recommendations for literature reviews (Paul \& RosadoSerrano, 2019; Paul et al., 2017) and on previous reviews on the use of QCA in specific areas or research (Rihoux et al., 2011; Berger, 2016; Verweij and Trel 2019). Our goals are to identify and understand potentially relevant traditions with implications for the topic studied; to detect themes, theoretical perspectives and procedures; and to identify gaps and promising research avenues (Paul \& Criado, 2020).

We used the Web of Science between 20 June and 7 July 2020. First, to identify the population of articles, we limited the search to articles in English published in journals indexed in the Social Sciences Citation Index database. Because QCA was introduced in 1987, we limited the scope to publication years 1987-2020. Second, to identify specific articles we used two families of terms. For the family of terms related to QCA methodology, we searched for "qualitative comparative analysis" or "QCA" in the title, abstract and keywords. ${ }^{4}$ We checked that other similar terms, such as fsQCA and csQCA, were not excluded in the above search. For the family of terms related to science, technology and innovation, we explored different meaningful combinations representing the conceptual space of the research area. We initially used the discrete terms "science" and "technology". Because we found very few articles, we added "innovation" to compare distribution in different domains. After several checks we found that the search did not capture all the related articles. We also included other terms that represent significant sectors and activities in the whole area. In addition to "science", "technology" and "innovation", we used the following terms: "research and development", "R\&D", "universit*" (to cover variations of the term university), "higher education", "laborat* (to cover variations of the term laboratory", "knowledge transfer" and "technology transfer". To make the search accurate and avoid false positives, we limited the search for the above family of terms to the title and keywords.

Third, we checked that the articles resulting from these operations were concerned with our goal. In order to be included, an article had to focus on meaningful topics for science, technology and innovation, or related activities, levels of analysis and sectors. We excluded a small amount of articles that were clearly outside the scope of our search (less than 5\%). When in doubt, we maintained an article to ensure inclusiveness. We also retained methodological articles that mention implications for this area of study. We found that most of

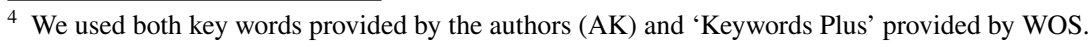




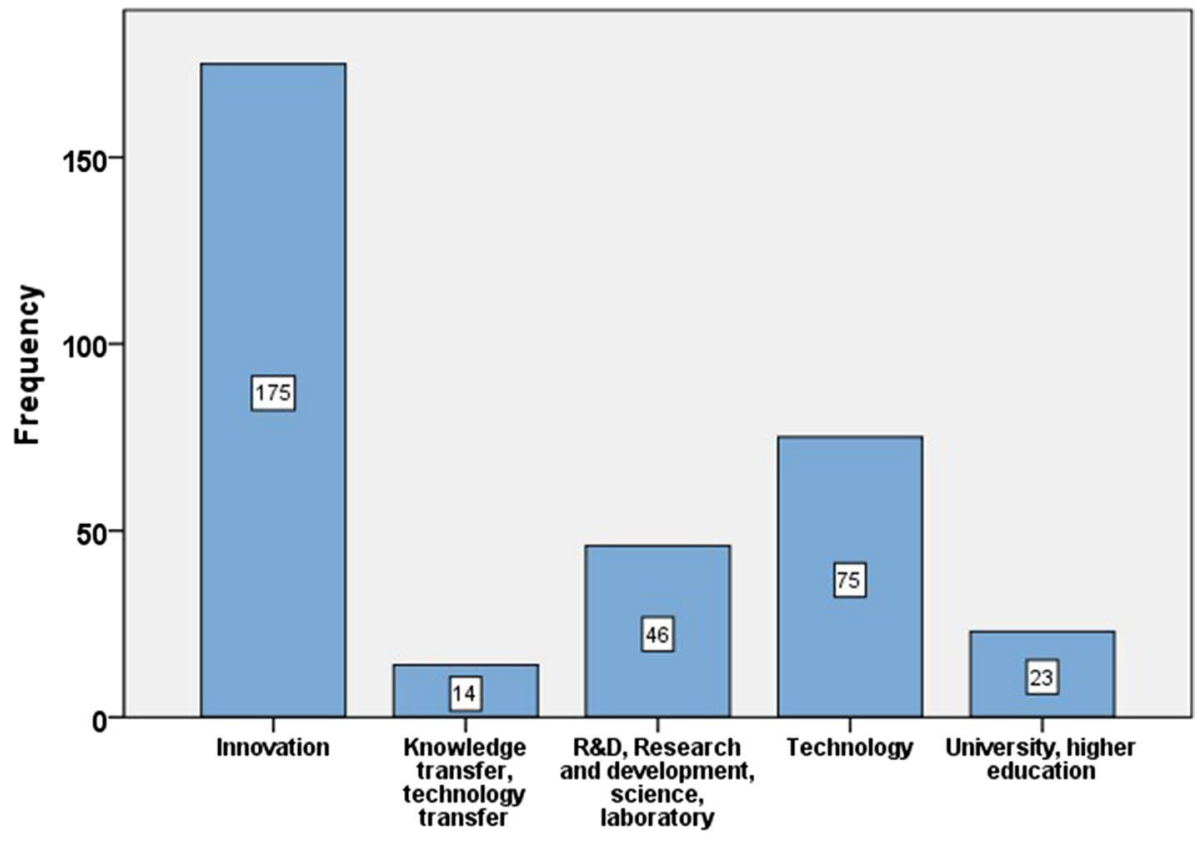

Categories of the conceptual space

Fig. 1 Distribution of publications in the categories of the conceptual space

the articles were about firm innovation in issues of an organizational, economic and social nature beyond science and technology. Nevertheless, because our search was accurate and had a good coverage of existing research, for comparative purposes we decided to work with the whole group of articles. Therefore, our source provides a map of the use of the QCA in knowledge and innovation and not only in science and technology. The final set is composed of 221 articles.

\section{Results}

Most published research is very recent: 193 articles were published from 2016 onwards. A disproportionate amount of the articles is concentrated in generic business and management journals. In particular, the Journal of Business Research has an overwhelming presence (108 articles). The following journals in number of articles are Technological Forecasting and Social Chance (TFSC) (7 articles), Industrial Marketing Management (6 articles), International Entrepreneurship and Management (5 articles) and Management Decision (4 articles). There are a few articles in the leading journals in the research field of innovation studies (SPIS). In addition to TSFSC, the main ones are Research Policy (4 articles) and Technovation (3 articles). In contrast, we found no article in Research Evaluation, Science and Public Policy, The Journal of Technology Transfer or other main journals in this field. Neither did we find any related article in the top journals in the STS research field (Social Studies of Science, Science Technology and Human Values, Minerva, etc.), nor 


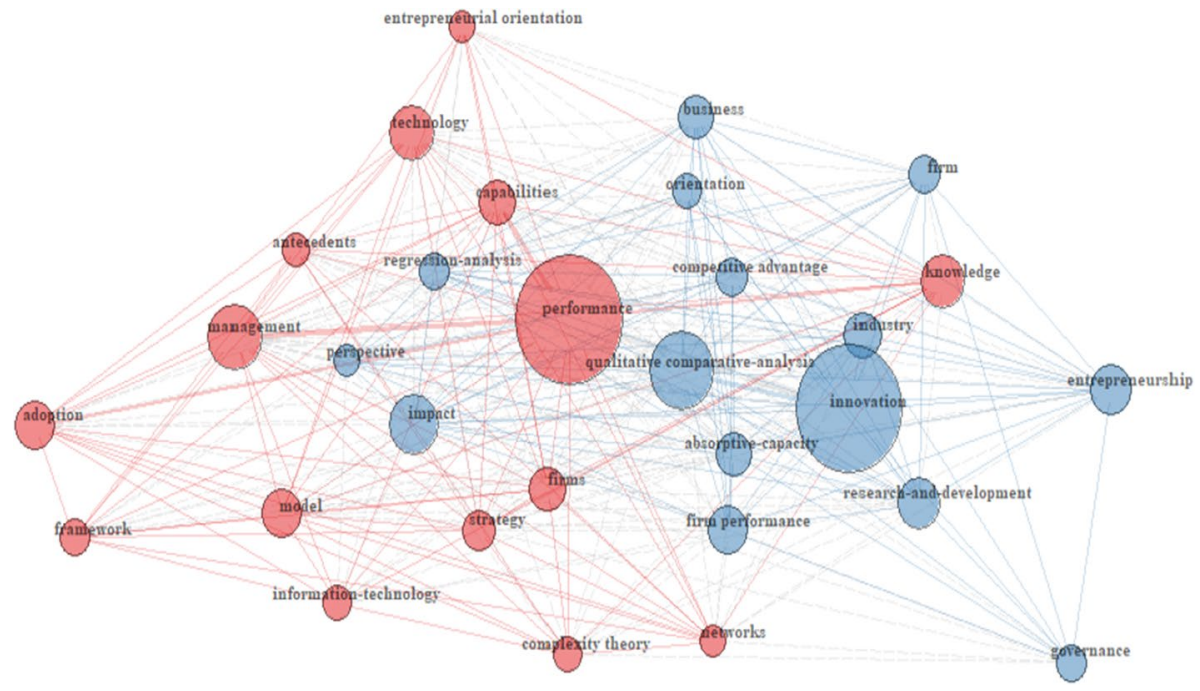

Fig. 2 Keyword co-occurrences

in journals specializing in quantitative science and technology studies (Scientometrics ${ }^{5}$ and others). This concentration is a highly significant contextual factor since it largely determines the focus on sectors and topics.

Figure 1 shows distribution based on the terms representing our conceptual space. ${ }^{6}$ Most articles are related to innovation: 175 articles were selected because they included the term "innovation" in the keywords or title. The term "technology" was included in 75 articles. Only four articles included the concept "science". We therefore merged this category with the following. "Science" or a related term ("R\&D", "Research and Development", "Laborat*") figured in 46 articles; "higher education" or "universities" appeared in 23, and 14 articles included the terms "knowledge transfer" or "technology transfer".

A closer look at article content confirms that most focus on firms and very few on universities, labs, research centres or knowledge transfer organizations. A small group of studies targets other micro-level units, such as projects of programmes, research groups and individual researchers. None focus on research outputs (articles, patents, books, etc.) or journals. Importantly, most of the articles on firm innovation highlight non-technological innovation. The graph of keyword co-occurrences (see Fig. 2) is useful to visualize the main issues of interest. Although R\&D and technological innovation are present, other issues related to the broader meaning of innovation are the most important, such us "entrepreneurship", "adoption" and a group of words that reflect the tradition of evolutionary economics of innovation studies (Fagerberg et al., 2013) ("absorptive capacity", "capabilities", "knowledge", "antecedents" and "entrepreneurial orientation"). Overall, the main interest is in firms' "performance" and the conditions that affect it. The state of research

\footnotetext{
${ }^{5}$ Interestingly, when finishing the final review of this article, the first article in Scientometrics based on QCA was published (Liu et al., 2020). It uses a sample of 630 researchers associated to mobility programmes in China. The justification of the method is based on the complex configurations contributing to the high research performance of researchers.

${ }^{6}$ We used the first word as it appeared in the title and keywords. Results from a combination of two keywords show the same concentration.
} 
reflects the multiple facets of innovation, including process, organizational, distributional and commercial innovation, in addition to R\&D and technology.

Given the concentration of existing research, our strategy was to assess the use of QCA in significant domains of science, technology and innovation (not only innovation), and in different sectors (not only firms). Our decision was based on several recent reviews of the use of QCA in business and management from co-citations and bibliometric coupling (Seny-Kan 2016; Berger, 2016). When using the same techniques in our data set, we found a very similar pattern to these previous studies regarding the knowledge base and the research front of innovation management in firms. In order to avoid redundancy, we decided to concentrate on a qualitative review from a selection of articles that illustrate our purpose.

We began our selection with the most cited articles (average citations in the last 5 years), classified separately according to the terms of our conceptual space (see Table 5 of the appendix). We then selected the first 10 articles in each category, eliminated repetitions and articles dealing with methodological issues and found that the thematic bias remained. The concentration in a small group of business and management journals resulted in a list where the majority of the studies focused on firms at an organizational level of analysis. To avoid this bias, we limited the appearance of articles with the above characteristics to three in each category. To select the remaining articles, we scrolled down the ranking in each conceptual category until finding at least the same number of studies that highlighted other levels of analysis (individual/team, project, territorial) and other sectors (university, research centres, public administrations, societal/civic society). This procedure enabled the inclusion of studies that illustrated the different uses of the method, while maintaining the criteria of relevance. The final selection is composed of 36 studies that were revised in depth. When reviewing the selected articles, we asked the following questions: Why is QCA applied? How is it applied? What are the main results?

Why is the method used? The most important reasons for applying QCA in a particular setting are (1) the possibility of capturing a higher degree of complexity, (2) the appropriateness of the approach for analyzing small sample sizes and (3) the existence of different combinations of characteristics producing an outcome rather than analyzing net-effects (Mas-Verdu et al., 2015; Glaesser et al., 2009; Kraus et al., 2018). This is in line with the arguments made by several researchers who have studied the application of QCA in other fields, such as public policy (Rihoux et al., 2011), planning (Verweij and Trel 2019) and others.

The method is present for mainly instrumental reasons. It is justified when attributes of the units of analysis are worthy of investigation but cannot be captured by traditional variables and statistical methods. Numerous studies conduct the analysis at an organizational level (Ganter \& Hecker, 2014; Guadix et al., 2016; Woodside \& Baxter, 2013). Tracing a pattern of the specific outcome analyzed is challenging due to the diversity of applications, although two groups of outcomes are clearly identified: general firm performance and innovation performance (Chen et al., 2013; Mikalez and Patelli 2017). Studies at a territorial level are usually justified because of the smaller samples due to the limited number of regions or countries (García-Ávarez-Coque et al., 2021; Roundi et al., 2018). Territorial performance in terms of innovation outputs, and other related economic indicators, creates the parameters for some of the outcomes (Khedhaouria et al., 2017; Proksch et al., 2017). Studies at group or individual level are less frequent and focus mostly on motivations and strategies of significant agents, such us customers (Ordanini 2014; Wu et al., 2015), professors (Coburn et al., 2012; Ryan \& Berbegal-Mirabent, 2016) and students (Ding Pappas et al., 2017; Tho, 2017). Other units of analysis, such as projects and programmes (Abbate et al., 2019; Bakker et al., 2011) are 
also used, although they represent a small part of the studies. Some studies capture insights at the intersection of two different sectors, such as universities and firms (Bacon et al., 2019; Berbegal-Mirabent et al., 2015) and public administrations (Osabutey \& Jin, 2016). Finally, some studies explore the societal sector, especially those focusing on innovation adoption by individual citizens (Wu et al., 2015; Gunawan \& Huarng, 2015).

How is it used? QCA can be used for a range of purposes from exploration to hypothesis, or ideal type testing (Berg-Schlosser et al., 2009). Although it was initially used for exploration purposes, the observed trend in the latest research is its application as a holistic method covering all analytical questions. The method is therefore mostly used to detect new relationships between phenomena and to develop hypotheses or propositions from existing theories. This is one of the reasons for its broad presence in business and management (Ordanini and Maggio 2009; Aversa et al., 2015; Ganter and Haker 2014; Cheng et al., 2013; Cannaert et al., 2019; Poorkavoos et al., 2016).

The specific technique (Boolean or fuzzy set) is a matter of the nature of measurement that can be assigned to the units of analysis. One to five gradations and fuzzy-set techniques are used when possible, though dichotomous codifications are common (Aversa et al., 2015; Bakker et al., 2014). Some studies are used in large samples because of assumptions about the distributional nature of the phenomena (Torugsa and Arundel, 2017; Saka-Helmhouit et al., 2019; Ruiki et al., 2017). On occasion the argument for using QCA is to enable results comparisons with other research methods (Xie et al., 2016; Gunawan \& Huarng, 2015; Mikaleff and Pateli 2019). A multi-method approach as an integral part of QCA is sometimes applied, for instance to contrast values assigned to the conditions or outcomes. This decision is mostly associated with the suspected configurational and therefore systemic nature of an outcome, rather than the lineal nature of a causal explanation (Woodside \& Baxter, 2013).

In consequence, the maturity of QCA as a stand-alone application method is subject to discussion and cannot be confirmed since larger samples might apply other forms of quantitative analysis. Smaller samples, on the other hand, could apply other qualitative methods, such as descriptive and hermeneutic observations. The most common implementation is found when the object of study is captured by qualitative observations, in addition to a research strategy that seeks a range of explanations based on the assumption of non-linearity of discrete variables The method also has some inconveniences in terms of theoretical considerations, the complexity of configurations, calibration and causal inferences. Researchers new to the method are usually prevented from automatically using it. They are advised to consult publications discussing specific disadvantages, as well as "goop practices" to cope with them. These challenges and possible opportunities are discussed later in Sect. Discussion: some challenges and directions for future research.

This literature review provides information about how the method is used and why, and the results it yields. However, explorations made for this article reveal that a single literature review has some limitations for discussing its usefulness in science and technology because of the few experiences outside businesses and innovation. Therefore, a useful way to test usage is to apply the methodology to an empirical case. We have selected a niche that is particularly appropriate: knowledge transfer in local innovation systems. 


\section{An empirical application: the study of university-industry relationships in innovation systems}

\section{Why is QCA useful for studying knowledge transfer in local innovation systems?}

Knowledge transfer, broadly understood as the process by which actors (individuals or groups) use knowledge produced in a different organizational or institutional domain (Bozeman et al., 2013), is a difficult phenomenon to observe. The actors that intervene have different capacities. Various types of activities are involved, as well as different sources of information and a variety of channels. Impacts are also different depending on the actors participating (Rasmussen \& Borch, 2010; Huggins et al., 2012; Corral de Zubielqui et al., 2018). Moreover, knowledge transfer is especially difficult to observe in SMEs. There is a marked contrast between the evidence available from high-tech firms and SMEs, particularly in terms of the factors that influence knowledge acquisition from universities (Corral de Zubielqui et al., 2015; Dada \& Fogg, 2016; Poorkavoos et al., 2016). There are also challenges for measuring exchanges between universities and SMEs. An important current of research is based on patents and their connection to publications and other documentary sources (Woltmann \& Alkærsig, 2018). There is substantial evidence about spin-off and start-up companies as they are easily identifiable and make greater use of the university resources available (Woltmann, 2012). The abundance of survey-based studies on university-industry links has revealed that influential factors include firm size, technological intensity of the industrial sector and organizational capacities (Perkmann et al., 2013). Also considered important are geographical proximity to the university, contacts and social capital (Padilla-Meléndez et al., 2013; Thorpe et al., 2005).

However, this evidence becomes more complicated when we move to local innovation systems in peripheral environments (Copus et al., 2008; Martin \& Simmie, 2008). The main actors interacting with universities are companies in the surrounding area. They are usually small, family-owned, have few graduate employees, and management is barely professionalized. The productive sectors are not generally technology-intensive. Traditional products, services and sectors based on local knowledge are common. Moreover, SMEs have greater difficulties finding suitable partners owing to limited access to knowledge networks (Buganza et al., 2014). From the university perspective, relationships with SMEs are also fraught with obstacles. Although regional development is the objective of many universities, it is difficult to know how knowledge transfer really takes place (FernándezEsquinas et al., 2016). Obstacles to research create a distorted picture of the university in peripheral environments, rendering these activities largely invisible (Benneworth, 2019), although a flux of collaboration and exchanges may exist. At present, many universities are surrounded by SMEs that find useful resources in nearby departments and research groups, and many researchers are associated with them both formally and informally. In sum, knowledge transfer and innovation operate in different ways depending on the environment. It has often been argued that the process is systemic (Benneworth, 2019; Porkavoos et al., 2016). The presence and combinations of different factors that can be found at local and organizational level determine the pathways to knowledge exchange. In other words, different constellations of interconnected elements may contribute to obtaining the same outcome regarding types of knowledge transfer.

The specific configurations in place are difficult to study because of information deficits. Firstly, very few SMEs use the codified results of R\&D and most do not enter into research-intensive contracts. Instead, they demand more services, such as consultancy and 
laboratory analysis (Brown, 2016; Wright et al., 2008). Hence, it is not possible to use habitual science metrics, such as citations of publications in patents. Secondly, administrative data sources are usually scarce. Many university-industry relationships are decentralized. SMEs often approach professors directly rather than knowledge transfer offices (Fernández-Esquinas \& Pinto, 2014; Pinto et al., 2014). They use personal networks thanks to proximity and personal trust, and formalize contracts only when there is an economic exchange. It is difficult for university managers to learn of these activities. Moreover, many universities keep no registers where the activities with the collaborating firms can be observed. Thirdly, the possibility of carrying out surveys is limited due to barriers imposed by firms and high costs. More often than not, the only possibility is an online survey. Online questionnaires pose limitations for measuring complex objects and, on occasion, it is difficult to find the right profile of respondents to provide information about the firm (Ramos-Vielba \& Fernández-Esquinas, 2012). Statistical surveys also pose limitations for observing the multiple conditions that may contribute to the same outcome.

Consequently, it is often necessary to use case studies based on interviews and other qualitative procedures. Qualitative methodologies based on detailed long-term observation generate rich information on social interactions, motivations, meanings and context. Many important aspects can be captured mostly by direct observation and processed by hermeneutic interpretation. This information is difficult to systematize (Franklin, 2012) and to connect to a causal rationale. Although some qualitative approaches implicitly assume the distributional nature of conditions that contribute to a given outcome, these processes are difficult to observe by manual procedures. Qualitative observations alone have some limitations for explaining the determinants of knowledge transfer (Álvarez-Coque et al., 2017). A consequence of this situation is the fragmented nature of research (Gherardini \& Nucciotti, 2017). In particular, one barely studied aspect is university-industry transfer in peripheral, local innovation systems. Knowledge transfer is therefore an area where QCA offers potential applications. Below is a study of a local innovation system. It explores how this methodology can be used and detects important determinants and outcomes of university-industry collaboration. The reasons for using QCA in this context are both the distributional nature of the outcome and the existence of a small number of cases. In addition, qualitative observations helped to capture dimensions that are not available in the form of indicators.

\section{Research site}

The study is located in the local innovation system of Cordoba, Andalusia, in southern Spain. The province of Cordoba has a population of 750,000, of which 340,000 live in the capital. Important economic sectors include agriculture and stockbreeding, agri-food and services. Manufacturing and heavy industries are limited. Most firms are independent entrepreneurs (49\%) and SMEs (37\%). Only six percent of the manufacturing industry belongs to high-tech sectors and $15 \%$ to medium technology sectors. In the services sector, high-tech firms make up 4\% (Cordoba Chamber of Commerce 2017).

The main research organization is the University of Cordoba (UCO). Founded in 1972, it has ten faculties, around 15,000 students and 1,400 professors. It specializes in agricultural sciences, biology and medicine, as well as other areas associated with a generalist university, including ICT, law, economics, education and humanities. In terms of scientific 
production, it holds position 26 of 73 in the ranking of Spanish universities. It manages an average annual budget of four million euros from contracts for research and services, with around 200 contracts per year. It is considered a medium-sized university, though somewhat above the national average in scientific production and transfer. The local innovation system is not availed of a wide range of knowledge producers or interface organizations adapted to local industry. The UCO is therefore the dominant actor. This generates increasing demands on its role as a strategic local agent, through a combination of training, research and services. Knowledge transfer activities are carried out thanks to the legal possibility for university professors to enter into contracts with firms. ${ }^{7}$

The local innovation system is polarized between a small group of high-capacity firms, with close ties to the university, and numerous SMEs in traditional sectors. The science and technology park, of which the university is a major shareholder, is a prime example. It houses several high-tech firms. This location enhances links to university research groups, while facilitating access to funding sources for R\&D. This small group of firms congregates the university's patent licences, $R \& D$ contracts and participation in $R \& D$ projects funded by public programmes. Several medium-sized and large firms located in the province regularly demand technical services and training. A larger group of SMEs require specific services and maintain relationships that usually go unnoticed. This group of firms uses a variety of collaboration channels through $R \& D$ contracts, laboratory testing, consultancy and educational activities, many of which are the result of personal connections between professors and entrepreneurs. In sum, it is a typical case of a peripheral environment where business effort in $R \& D$ and innovation continues to be a challenge for the productive sector and where the local university is one of the fundamental actors for knowledge transfer. ${ }^{8}$ The indicators available leave numerous activities hidden because of the difficulty of having them registered and codified. One aim of this study is to unveil and measure them for research purposes.

\section{Fieldwork and data}

We have used 40 case studies of firms of various sectors, sizes, ownership and types of link with the university that represent different forms of knowledge transfer and conditioning factors. The firms are located in the metropolitan area and the province. The choice of productive sectors is based on the UCO's catalogue of technological offerings. It includes agro-business, manufacturing and services of several types. Our conception of the cases included information about the firm, as well as contextual information about the partners in the university and the activities developed with them. The definition of the expected outcome was an important criterion for the selection of cases. We chose firms with a recent formal contract or agreement with the university and firms that had no formal agreement, but whose characteristics rendered them liable to make demands on the UCO (such as working in knowledge-intensive services, or, failing that, whose organizational and

\footnotetext{
7 Article 83 of the 'Organic Law of Universities' (Law 6/2001, of 21 December) lays down that research groups can enter into contracts for scientific, technical or artistic work and for training activities. University statutes set out authorization procedures and the distribution of part of the amount in the form of a salary bonus. Once a formal contract is granted by the university, it is carried out in a decentralized manner, and the activities are decided by the professors and the firms.

${ }^{8}$ A detailed analysis of the local innovation system can be seen in a research project carried out by the authors of this article (Fernández-Esquinas et al., 2019).
} 
personnel characteristics might lead them to have some links with university professors). The firms chosen mostly correspond to low technology sectors, although several firms are high-tech, including spin-offs. They form a strategic sample of firms with actual or potential demand for university R\&D services.

For each firm chosen, a file was prepared using information available (web page, catalogues, news in the press, university records, etc.). This file was used to adapt interviews to the situation of each firm. Subsequently, the person chosen to respond had the most suitable profile (managing director of the firm, who was often an owner in the case of SMEs, or the person in charge of innovation activities), and a meeting was arranged. At least one structured interview was carried out at the main offices of each firm. During the meeting, a visit was made to the firm's facilities. The interviews were recorded, and all relevant information was noted on file. The interviews lasted around $120 \mathrm{~min}$ on average. Both documents and interviews were structured in a set of dimensions that allowed detailed observations. From the rich information collected, Table 2 gives the dimensions for which our conditions and outcomes were organized according to our main hypotheses.

\section{Observational dimensions and hypothetical conditions}

The research questions are as follows: What factors led firms to work with the university? What were the main groups of determinants for establishing a contract for the different kinds of activities? QCA is used to explore the conditions that influence the way in which firms do or do not enter into relationships with the university through a commercial-style contract. Our initial criterion to specify the observational outcomes was to focus on firms that have a contractual relationship with the university for both original R\&D and services, compared to those that do not. An important contextual factor for our study is that university records provide no detailed information about the activities undertaken under contract. A single formal contract can encompass various activities of different scientific or technological content. Activities can be based on an R\&D project, or a range of technical services and consultancy. They require varying levels of collaboration intensity with the university and also different levels of capacities from firms.

Prior studies in the region indicate that firms of varying profiles embark on applied research and university services (Fernández-Esquinas et al., 2019) for different motivations and capacities. For that reason, the first classification of outcomes consisted in separating collaborations corresponding to an $\mathrm{R} \& \mathrm{D}$ project from those corresponding to services not entailing original research. In this way, it is possible to disentangle conditioning factors which might contribute to the firm embarking on projects or service contracts. These differences can only be detected through detailed observation of the activity covered by a formal contract and are therefore an advantage of the methodology used. We separated the activities that correspond specifically to R\&D projects (PROJ) and services (SERV) in the past 5 years.

As conditions (or conditioning attributes that may influence the outcomes), we selected dimensions habitually addressed by the literature as indicating a possible determinant on university-industry links. We acknowledge that empirical research on science and industry relationships uses a large array of detailed variables for exploring influences on knowledge transfer, including information about productive sectors, technological content, organizational characteristics of firms and universities, finance and the internal structure of projects (Perkmann et al., 2013). Our case studies collected this fine-grained information. However, many of the potential variables do not make sense when adapted to specific local features. 


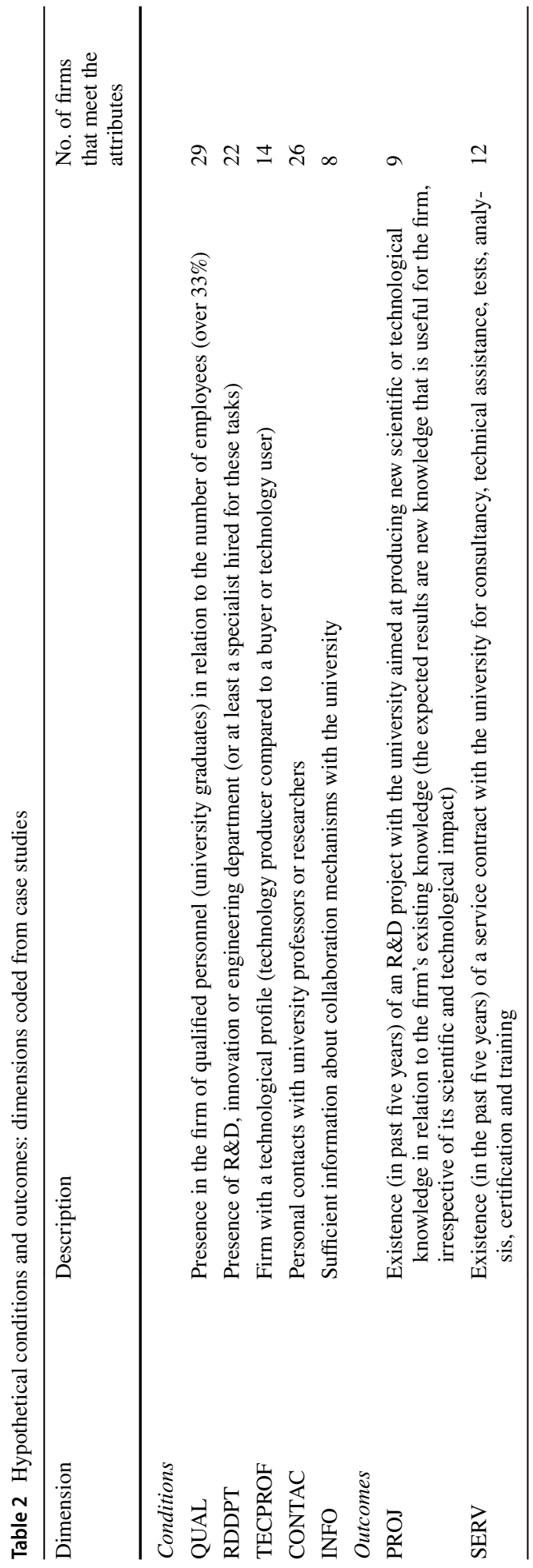


When defining operational dimensions, we concentrated on those that are meaningful for comparing firms of the region's industrial fabric, mostly SMEs working in low-tech and traditional sectors. Following are the starting hypotheses:

H1 Conditioning factors related to absorptive capacity. For these observations we used an adaptation of the well-known absorptive capacity hypothesis defined as a set of organizational routines and processes by which firms acquire, assimilate, transform and exploit knowledge to produce a dynamic organizational capability (Zahra \& George, 2002). High levels of absorptive capacity are usually grounded in elements internal to the firm that help to recognize the value of new external knowledge and to incorporate it in business activities (Cohen \& Levinthal, 1990). Therefore, the relationship with the university may be facilitated by specifically qualified personnel, by the existence of a minimum organizational structure for innovation and by technological activity. These attributes can enable firms to interact with an external agent and increase their capacity to absorb knowledge. The presence of qualified personnel, the existence of an organized internal structure for innovation, such as a department or specific unit for innovation, and the firm's technological profile are expected to result in contracts with the university.

H2 Conditioning factors related to contacts and knowledge of the university. The hypotheses that guide these observations are bound up with social capital and knowledge about the university (Tsai, 2000). Firms with personal connections to university professors are more likely to identify a potential benefit and obtain a higher degree of confidence that helps formalize relationships. Moreover, firms with sufficient information about contractual mechanisms with universities also have better conditions for working with them. These conditions are expected to improve the chances of arranging R\&D projects or services with the university.

\section{Coding and technical procedure}

The next step consists in identifying the attributes of firms that function as conditioning factors in our hypotheses. They are interpreted as the combination of features that contribute to explaining the observed outcome: the existence of a project or a service contract with the university. After detailed observation of the information available for each firm and for its university partners, we classified the dimensions in accordance with exhaustive and mutually excluding criteria. For the attributes related to absorptive capacity, we considered whether the firm has a special presence of graduates (QUAL), an R\&D department (RDDPT), or at least a person in charge of those functions, and a technological profile (TECPROF). For the attributes related to information and social capital, we considered whether the firm has personal connections to university professors (CONTAC) and sufficient information about bridge-building mechanisms with the university, such as technology transfer offices and administrative procedures (INFO). The description is included in Table 2.

A dichotomous classification was used for these attributes. The conditions clearly pinpoint the presence or absence of a characteristic. The reasons for a dichotomous classification are the absence of documentary information or insufficient direct evidence for a meaningful gradation in a scale. Contrasts between researchers who observed the cases allow for more trustworthy dichotomous classifications. The only dimension that would enable a gradation is presence of university graduates in relation to the number of employees. In this dimension, one-third was used as a cut-off point because it is considered the threshold at which the firm 
Table 3 Consistency (cons) and coverage (cov) for firms with R\&D PROJECTS or SERVICES

\begin{tabular}{llllll}
\hline Condition & \multicolumn{2}{l}{ PROJ } & & \multicolumn{2}{l}{ SERV } \\
\cline { 2 - 3 } \cline { 5 - 6 } & Cons & Cov & & Cons & Cov \\
\hline QUAL & $0.89 *$ & 0.28 & & $0.83 *$ & 0.35 \\
RDDPT & $\mathbf{0 . 6 7 * *}$ & 0.27 & & $\mathbf{0 . 7 5} * *$ & 0.41 \\
TECPROF & $\mathbf{0 . 7 8 * *}$ & 0.50 & & 0.58 & 0.50 \\
CONTAC & $1.00^{*}$ & 0.35 & & $1.00^{*}$ & 0.46 \\
INFO & $\mathbf{0 . 6 7 * *}$ & $0.75 * *$ & & 0.58 & $\mathbf{0 . 8 8 * *}$ \\
\hline
\end{tabular}

Values with * are greater than or equal to 0.8

Values with $* *$ are greater than or equal to 0.6 and lower than 0.8

can embrace complex activities that facilitate knowledge transfer with a university. Tests were made with the two types of measurements for this dimension (fuzzy set and Boolean options), although the solutions gave no differences that would alter the interpretation. Therefore, we used the option crisp-set QCA for dichotomous observations.

\section{Analysis and results}

Table 3 gives the consistency and coverage of the conditions obtained with firms that have an R\&D project (PROJ) or services contract (SERV) with the university. Values greater than or equal to 0.8 , which represent the most significant probabilities, are marked with *. Values greater than or equal to 0.6 and less than 0.8 , which can also be considered important, are marked with **. The following subsections outline each step of the analysis.

\section{Analysis of necessity: supersets of results}

In this step the condition will be necessary for the outcome ( 1 is the probability of associated consistency). The attribute systematically associated with having a contract with the university was personal contacts with university professors. $100 \%$ of the firms undertaking projects or service contracts know or have personal contacts with university professors. Therefore, this characteristic is essential ${ }^{9}$ for a firm to successfully have a formal relationship associated with knowledge transfer.

This table shows separately the relevance of the firm's characteristics in both activities. The main conclusions from the consistency column are as follows:

- Of the firms that have undertaken a project (PROJ), $89 \%$ have a special presence of university graduates (QUAL), 67\% have an R\&D (RDDPT) department, 78\% produce technology (TECPROF), 100\% have contacts with university professors and $67 \%$ have sufficient information about collaboration mechanisms (INFO). All of them are therefore significant characteristics associated with $R \& D$ projects.

${ }^{9}$ In set theory, it is a necessary condition (a superset) for both results. 
- Of the firms that have entered into a service contract, $83 \%$ have a special presence of university graduates (QUAL), 75\% have an R\&D (RDDPT) department, 58\% produce technology (TECPROF), 100\% have contacts with university professors and $58 \%$ have sufficient information about collaboration mechanisms (INFO). In addition to contacts with university professors, the most significant conditions reflect absorptive capacities related to human resources and organizational arrangements.

\section{Analysis of sufficiency}

Step a: subsets of results. Sufficiency analysis aims to pinpoint the conditions that are subsets of results. In this case, the condition will be sufficient for the outcome (1 is the probability of associated coverage). The main conclusions drawn from the interpretation of the coverage columns in Table 3 are as follows:

- Availability of information is the most significant characteristic shared by firms that have undertaken a project, followed by technological profile. $75 \%$ of firms that have information about collaboration mechanisms with the university (INFO) and $50 \%$ of $R \& D$ producers have participated in an $R \& D$ project. The other characteristics have scant importance in this aspect.

- For firms with a services contract, the most significant condition is also the availability of information: $87 \%$ of firms that have information have held a services contract. Technological profile is next in importance. As for technology producers (TECPROF), 50\% have also held a services contract. The availability of university graduates, an R\&D department and personal contacts with university professors are not significant compared with the previous conditions.

Step $b$ : truth tables. Tables 6 and 7 of the appendix show the truth tables. These tables only include combinations for which there are empirical data being observed in practice. The percentage of cases that verify the outcome (PROJ or SERV) and the number of specific cases are shown for each combination. Moreover, combinations for which this percentage is higher than zero are marked (that is, those for which the result has been verified in at least one case). The following evidence has been extracted from the interpretation of Tables 6 and 7:

- The last row of both tables reveals that of all 40 firms analyzed, six verify the five conditions considered. Of these firms, $83 \%$ (5) have an R\&D project with the university (PROJ) and $100 \%$ have a services contract (SERV).

- No firm for which the outcome has been verified (PROJ or SERV) shows an absence of contacts with university professors.

Step c: solutions. The truth tables are used to identify combinations whose presence or absence are relevant and therefore to reduce the complexity of the initial data set. Table 4 shows the combinations of conditions that are sufficient for the existence of an R\&D project and a service contract with the university (that is, for PROJ and SERV). They are sufficient because the outcome is achieved if the conditions are present. Therefore, having contacts with university professors as well as being a technology producer are the options related to participating in an $R \& D$ project with the university (PROJ). In contrast, other options appear as possible for having service contracts with the university. Table 4 also 
Table 4 Results for the analysis of sufficiency with PROJECTS and SERVICES

\begin{tabular}{|c|c|c|c|c|}
\hline \multirow[t]{2}{*}{ Condition } & \multirow{2}{*}{$\begin{array}{l}\text { PROJ } \\
1\end{array}$} & \multicolumn{3}{|c|}{ SERV } \\
\hline & & 1 & 2 & 3 \\
\hline QUAL & & & O & $\bullet$ \\
\hline RDDPT & O & & O & $\bullet$ \\
\hline TECPROF & $\bullet$ & $\bullet$ & & $\bigcirc$ \\
\hline CONTAC & $\bullet$ & & $\bullet$ & $\bullet$ \\
\hline INFO & & $\bullet$ & & O \\
\hline Consistency & 0.22 & 0.50 & 0.18 & 0.18 \\
\hline Coverage & 1.00 & 1.00 & 1.00 & 1.00 \\
\hline Overall solution consistency & 0.22 & & & 0.83 \\
\hline Overall solution coverage & 1.00 & & & 1.00 \\
\hline
\end{tabular}

- presence of condition; $\bigcirc$ absence of condition

shows the consistency for each solution (that is, the probability that, given the specific result, each configuration has been verified) and the overall solution consistency for each result. It should be noted that in the overall solution for "projects" the consistency is low (0.22) compared to the consistency for "services" $(0.83)$. However, csQCA has provided only one solution for projects. This is grounded in the previous steps of the analysis with the absence of the conditions (that is, the "mirror" analysis for the firms "without projects" and "without services"). In such case, the consistency of the overall solution is 0.68 , although a cautions interpretation is recommended for the firms characteristics that facilitates the contracts of research projects in comparison to services (the complementary analysis for No PROJ and No SERV and the consistency values are included in Table 8 of the annex).

\section{Findings}

The overall results of the analysis are interpreted through combinations of attributes in firms that appear as necessary or sufficient conditions for the existence of a project or service contract with the university. Hence, the use of the metaphor winning combinations depicted in Fig. 3. For R\&D projects we found only one option: the combination of personal contacts with university professors and a technological profile. These two characteristics improve the chances of working with the university (one connected to social capital and the other to the firm's absorptive capacity). Having contacts with professors and being a technology producer increase the likelihood of identifying the knowledge available and enhancing the capacity to connect with university research groups in order to create new knowledge.

The combinations, and therefore the different possibilities of being involved in service contracts, are more diversified. An initial option is possessing the right information, coupled with a company profile as a technology producer, and not absorptive capacities. A second option is having personal contacts (in the absence of qualified personnel and a specialized department for R\&D or innovation). These are firms with long-term relationships 
based on trust. A third option is associated with greater absorptive capacity, namely, qualified personnel and an R\&D department, albeit combined with information.

In conclusion, this study suggests that, in this kind of environment, the process of knowledge transfer has a systemic (or a configurational) nature. It is facilitated by the presence of several "ingredients", though for specific activities different recipes contribute to the same outcome. It suggests that there is no one-size-fits-all university policy for knowledge transfer with agents in the surrounding environment. The qualitative observations of the rich information collected for the cases have helped to build a meaningful narrative behind the combinations detected. The findings show that the most immediate influence on improving potential university-industry relationships is to facilitate information exchange and personal contacts between research groups and firms in sectors that have some affinity with the university research portfolio. The findings also show that, regarding service contracts, there are other options depending on firm profiles: the presence of qualified personnel and basic organizational capacities of firms are important components. Therefore, a very important implication for interacting with the university entails having fluid relationships with university personnel. Knowing professors and their professional profile makes it easier to identify any likely area of interest for firms, in accordance with their specialization. Graduates and internship students in firms also serve as a link between university professors and companies. Both smooth the way for information and direct access, complement the activities of knowledge transfer offices and technological offering, and boost confidence in collaborating with the university. The study also reveals some difficulties. Operational outcomes and the inclusion of other conditions may lead to other paths to the outcome of interest. Therefore, the mechanisms and processes that explain knowledge transfer need to be complemented with specific studies able to capture different influences in similar situations. The more general implications of the pros and cons of the method are discussed in the next section.

Fig. 3 Winning combinations: conditions that facilitate projects and service contracts with the university

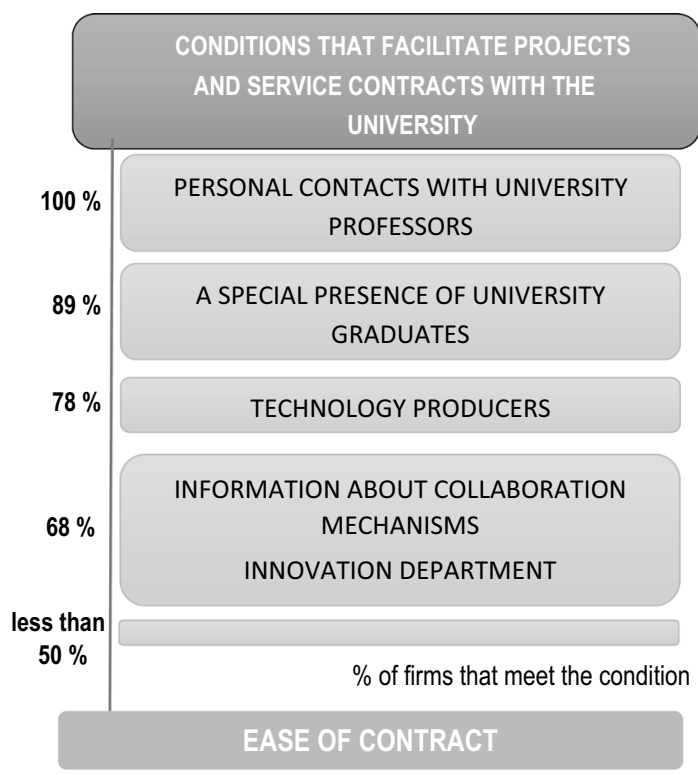




\section{Discussion: some challenges and directions for future research}

Based on the literature review and practical application, in this section we discuss the main challenges and opportunities when using QCA. We follow the suggestion that a common function of literature reviews is to offer insights related to theory, methodology and procedures in order to inform further research in a given area (Paul \& Criado, 2020). Accordingly, we firstly discuss the main theoretical and technical issues. Given the specific requirements and the associated difficulties when dealing with QCA, we interpret some challenges as sources of possible gaps. Secondly, we offer some future directions for research. A detailed discussion on the methodological options is not possible (for an updated account we refer, for instance, to Thomann \& Maggetti, 2020). Instead we use a more practical approach. We have selected some strategies, topics and illustrative examples with potential application for researchers working in science, technology and innovation.

\section{Main challenges}

In order to do justice to its underlying rationale, QCA should be understood not only as a technique but as a comprehensive research approach (Schneider and Wagememann, 2010). It is not for analyzing a random set of cases at hand; it is about conditions and outcomes. Potential problems often do not stem from the technical and financial practicalities of performing a study on a small number of cases and different sources of information accessible to a wide range of researchers. Rather, they come from the intellectual and methodological points of departure. The main challenges are associated with the requirements of transparency, justification and awareness (Wagemann et al., 2016). In this section we focus on the challenges arising from complex configurations, measurement and inferences.

The first issue is about the very notion of configurations. Configurational theory poses a dual challenge of a theoretical and technical nature. On the one hand, the configuration is best understood from a systemic perspective and should be viewed as a whole. It is a constellation of interconnected elements that has its own properties. The contribution to an outcome depends on the presence of specific elements. There is a need to develop theory that can account for the complexity of configurations, given that even with a small number of cases the theoretical combinations are extremely high (Fiss et al., 2013). Addressing complexity by adding dimensions results in additional problems. The number of possible configurations increases exponentially with the number of attributes considered. The existence of many conditions provides very complex results and hinders theoretically meaningful interpretations because the number of possible configurations may become overwhelming.

On other hand, this poses a technical problem related to the ratio between the number of cases and the number of conditions. Not all theoretically possible configurations actually happen empirically (the so-called limited diversity). QCA allows for a manageable account because it does not detect the possible but the empirical possibilities, although it poses the problem of disentangling meaningful mechanisms and avoiding meaningless options. The introduction of every additional condition in QCA doubles the number of truth table rows and therefore amplifies the existence of rows without empirical information. This situation results in findings that are based on too little variation of available cases. This problem cannot be avoided by increasing the number of cases. These cases can sometimes cluster in only a few truth table rows. The probability of inconsistencies thus increases because there is a very low portion of empirical information in comparison to the theoretically imaginable diversity. The high number of logical 
remainders makes the problem of limited diversity even more pronounced (Schneider \& Wagemann, 2012). In consequence, a central question in QCA is identifying what really matters for the configuration and what is expendable. Given that our understanding of the causal processes is always incomplete, theories are very important. The challenge to overcome too many options, inconsistencies and trivial elements in the combinations requires a theoretical hypothesis. For this reason, interpretation is closely dependent on the theoretical approach of departure when defining hypotheses.

The second challenging issue is about clear calibration when membership values are assigned to single cases. Statistical measurement is not the same as calibration, which involves interpreting measures in relation to external standards (Rihoux \& Marx, 2013). Sensitivity to small changes in calibration is also a challenge. Different calibration can cause a case to shift to another truth table row, meaning that the result of minimization may also change (Bennet and Elman, 2005; Cheng et al., 2013). Calibration of fuzzy sets based on external criteria forces the researcher to be explicit in determining the meaning of being at a certain point in a scale, the reason a certain case is more "inside" or "outside" a set, the qualitative thresholds separating values, and the meaning of floor and ceiling values. Consequently, calibration and measurement are highly dependent on concept formation. Any gaps in the definitions and conceptual constructs for classification are carried over the entire analysis and become gaps in the method itself.

A third point of attention is the challenge to draw deterministic (rather than probabilistic) inferences from a selection of cases. One reason is that in small groups of cases, the inclusion of only a single paradoxical case may influence the results and even lead to inappropriate conclusions (Gunawan et al., 2015). Although it is possible to identify necessary or sufficient configurations that produce an outcome of interest, the question about the mechanisms and processes that explain outcomes in similar situations is difficult to answer with the sole application of the method (Berbegal-Miravent et al., 2015). In order for this potential limitation to be considered, some studies recommend combining QCA with other methods to take into account the rationale of causal mechanisms and processes at work behind the conditions in the cases (Kraus et al., 2018; Schneider \& Rohlfing, 2016). A final shortcoming discussed in the literature is that the method is not well equipped to analyze case dynamics over time, unless case dynamics and change are included in the observation (Plewa et al., 2016).

As a consequence of the above challenges, the use of QCA is associated with "standards of good practice" that prevent the risks of automated and mechanistic application. In this sense, Schneider and Wagemann (2010), and more recently Gerrits and Verweij (2018), present a list of suggestions regarding a "good" QCA to be taken into account before, during and after the analytical moment of data analysis. In addition to careful selection of cases and concept formation, a review of these good practices extracts the following conclusions: (i) analysis of necessity must be performed separately before truth table analysis, so as to prevent wrongly claiming necessity of conditions; (ii) if the consistency scores of the truth table are too low, the data may include too many contradictory cases to warrant robust results; (iii) it is important to clear the treatment of logical remainders and avoid remainders that actually express theoretical assumptions that are impossible or that contradict the evidence; (iv) it is recommended that calibration rules and raw data matrix are provided to assess the quality of the analysis (Verweij \& Trell, 2019).

\section{How QCA can be used by STI researchers}

Our review provides a balanced assessment of the application of the method. Because of sensitivity to complexity, the ability to analyze small and medium groups of cases and 
the coverage of various types of information and units of analysis, several forms of added value can be identified for science, technology and innovation. They represent potential directions for future research.

A first application is with large-N. QCA was conceived mainly as a methodology for small groups of cases. However, recently it has been used to examine large-N phenomena with numerical indicators traditionally analyzed by tools based on the general linear model (GLM). Some authors (Rihoux \& Marx, 2013) consider that currently there are "two QCAs" since assumptions used with cases can be extended to large groups. At times, some data sets have configurational properties. It makes sense to identify combinations of causal conditions associated with an outcome instead of isolating the net-effects of individual explanatory variables. At other times, some authors find opportunities for integrating QCA with large N and approaches based on correlations and GLM. The two different philosophies can be used in hybrid strategies that seek trade-offs, for example, by reintroducing QCA solutions into a regression model to test for robustness, establish effect sizes and detect omitted variables in QCA. A future research avenue is to rightly identify complementarities between both approaches.

A second potential application is the systematic analysis of complex units of analysis, such us territorial units (Stanko and Olleros 2013), sectors, organizations and disciplines (BerbegalMirabent et al., 2015; Plewa et al., 2016), to which a configurational rationale may be applied. In these complex units, non-systematic information from ethnographies, interviews, focus groups, documents or others can be processed and integrated in observational dimensions (both conditions and outcomes). Common examples in the field of knowledge production can be mentioned. In the domain of information science, several types of documents can be observed and treated as units of analysis for which conditions and outcomes can be operationalized based on the careful observation of small $\mathrm{N}$ (articles, patents, books and doctoral dissertations, among others). Scientific journals as a whole can also be treated as complex units of analysis. In the domain of research establishments, individuals and informal aggregates can be subject to operationalization and calibration (research groups, disciplinary communities, etc.), in addition to formal organizations, ranging from departments and laboratories to large universities.

A third application is the triangulation of quantitative and qualitative information sources in the same unit of analysis, for instance, when the outcome is available in the form of indicators and the conditions should be constructed by qualitative observation. A useful example is any kind of research evaluation of a complex unit (a university department, a project, etc.) where publications and other outputs are at hand, but not the plausible indicators of a social, cultural or economic nature that contribute to such outcomes. The opposite sequence is also possible when the conditions are accessible in the form of indicators, but not the outcomes. Studies regarding the social impact of research are perhaps one of the most promising avenues for future research since the observations of internal processes of projects are usually the "black box" of studies focusing on performance (Fernández-Esquinas, 2020). In this type of application, the codification of complex sets of information into discrete dimensions helps map a fuzzy reality and is sometimes a preliminary step to codifying indicators if they are proven useful.

And finally, another potential application is for research evaluation purposes, or for policy intervention models seeking favourable or unfavourable outcomes of research and innovation policy (Tho \& Trang, 2015; Bennet and Elman 2005). In contrast to statistical tools, the identification of more than one path to an outcome is useful in real-life policy practice when different cultural and administrative traditions often call for differentiated implementation schemes (Audretsch et al., 2004). In particular, in research evaluation exercises of programmes, projects and organizations, the method allows for engagement in quasi-experimental designs to ground decisions in micro-situations. This design enables the evaluator to examine under which conditions a specific decision is effective or not in a transparent way, since it is easy to 
implement the operationalization of the dimensions, or to include them for further tests (Trequattrini 2019; Ospina-Delgado and Zorio-Grim 2016).

\section{Conclusions}

Throughout this article we have explored the use of QCA in science, technology and innovation. The structured literature review has shown that design and implementation have gained in sophistication and recognition in recent years. That said, at present it is only found in some domains, activities and sectors. Most studies correspond to business and management, and focus primarily on firms' innovation performance. In contrast, this methodology is scarce in fields dedicated to the study of science and technology, and few articles appear in the leading journals. Accordingly, few studies are dedicated to levels of analysis that are significant for the production and application of scientific knowledge (laboratories, departments, research groups and projects) and even fewer in research outputs (articles and patents).

The reason for this difference lies in the methodological preferences and work styles of the different research communities. Researchers in the STS research field prefer a more unstructured approach to their objects of investigation. They tend to use narratives and other types of qualitative techniques. Studies based on cases are not generally treated in an operational fashion. On the other hand, this method is barely used in purely quantitative approaches, which often depend on the data available, and assumptions about the distributional nature of outcomes are not frequent. In contrast, acceptance in management and policy fields is increasing. This may be a consequence of the conception of research as a more structured enterprise based on theory building when case studies are used. Hypotheses tend to be codified in a more positivistic fashion in an attempt to explain conditions driving innovation performance. Therefore, to date, QCA has fitted better with strategies for integrating qualitative observation in frameworks with a quantitative orientation, and not vice-versa. This is consistent with the growing presence of the methodology in the SPIS research field, mostly in management journals, and its gradual spread from firms to other complex organizations, territorial environments, programmes and projects.

As a way of illustrating and testing the methodology, we have applied QCA to a research problem that is especially relevant to discussing the pros and cons: the relation between university and industry in a local innovation system. Contributions from this study refer to both implementation and substantive findings. We have shown how knowledge transfer can be systematically examined in a peripheral environment distinguished by the presence of universities and firms that base their relationships on activities that go beyond codified research results. QCA has enabled us to operationalize dimensions that capture university-industry links and the causes that influence them. The findings show that knowledge transfer in local innovation systems generally remains hidden in the absence of a specific observation strategy. We have found different paths that contribute to engaging with the university. Knowledge transfer is facilitated by a mix of influences acting together, mainly fluid relationships with university personnel, adequate information and absorptive capacities represented by qualified workers and internal organizational arrangements. The analysis has been proven useful because it enables the systematic treatment of a phenomenon and shows the distributional nature of the process. It also uncovers some limitations: the influence of the information collected in order to obtain gradations instead of dichotomous classifications, the sensitivity of the dimensions to conceptual definitions, and the difficulties in making strong causal inferences.

These results have several implications for the use of data and methods in the social studies of science, technology and innovation that go beyond the application of QCA. Indeed, 
they have been part of a fundamental discussion on the nature of knowledge long before the practical implementation of this technique. Methods and approaches are closely interconnected and develop in tandem. How we get to know the word is a consequence of the ideas we start out with. At the same time, the methods we use shape theory and our fundamental assumptions. The usage of this method depends on the meta-theoretical points of departure when approaching science, technology and innovation. Meta-theoretical issues refer to both ontological (the premises about the deep structures of a social object) and epistemological assumptions (the conditions of the ways of knowing and learning about social reality). It is important to make these assumptions explicit because they determine research endeavours, communication of findings and interdisciplinary collaboration. They are especially meaningful when contrasting QCA with other methods, whether qualitative or quantitative.

In conclusion, we would like to highlight some unresolved challenges in the form of questions that are meaningful for the study of knowledge domains. The first issue is the treatment of causal complexity. An important consequence for research designs is the approach to configurational causation, that is, when causes are not isolated but mainly occur in combination. The main assumption is that a combination of attributes is essentially different from the effects of the individual elements. A parallel assumption is the rationale for explanations, the so-called abduction (or "retroduction") for establishing the contextual conditions that give rise to the particular mechanisms we are observing. That is, a likely conclusion derived from observation that does not positively verify it, but that is at least plausible and subject to verification. An important question is whether this approach to configurational logic and causality fits with our understanding of the production, application and distribution of knowledge (instead of, or in combination with, other meta-theoretical approaches based on GLM in which each variable is assumed to be capable of influencing the level of probability regardless of the values of other variables). The second issue is the way in which qualitative observations are approached, such as when ideas, values and behaviours are interpreted. Important questions are whether processing qualitative information obtained by interpretation (including hermeneutic) operationally through calibrations is worth it, and whether these calibrations are meaningful for integration in configurational and causal analysis.

The potential application of QCA in science, technology and innovation studies is closely related to how the above challenges are addressed. The legitimacy and possibilities for cross-fertilization of this methodology with others will therefore depend on its usefulness in illuminating research issues significant for scientific communities. In sum, following the review and empirical study provided in this article, we do not offer a definite recommendation for general application, or a critical viewpoint. The use of QCA in knowledge domains is still a work in progress, not a consolidated agenda. Inclusion in the established toolkit of scholars exploring scientific knowledge production, technology and different kinds of innovations will depend on the research community's meta-theoretical assumptions and methodological preferences when addressing typical problems. At the moment usage is advancing unevenly along various research streams.

\section{Appendix}

See Tables 5, 6, 7, 8 
Table 5 Selected studies in the categories of the conceptual space

\begin{tabular}{lll}
\hline Search categories & Level of analysis & Sector \\
\hline
\end{tabular}

Science, $R \& D$, Research and Development, Laboratories

Mas-Verdú et al. (2015)

Woodside and Baxter (2013)

Glaesser et al. (2009)

Guadix et al. (2016)

Ryan and Berbegal-Miravent (2016)

Khedhaouria and Thurik (2017)

Proksch et al. (2017)

Technology

Mikalef and Pateli (2017)

Gunawan and Huarng (2015)

Aversa et al. (2015)

Roundy et al. (2018)

Ruiqi et al. (2017)

Wu et al. (2015)

Abbate et al. (2019)

Innovation

Ordanini et al. (2014)

Ganter and Hecker (2014)

Cheng et al. (2013)

Ordanini and Maglio (2009)

Arundel (2017)

Cannaerts et al. (2020)

Saka-Helmhoiut et al. (2019)

Higher Education, Universities

Berbegal-Mirabent et al. (2015)

Plewa et al. (2016)

Pappas et al. (2017)

Coburn et al. (2012)

Sim et al. (2018)

Dinh (2017)

Ospina-Delgado and Zorio-Grima (2016)

García-Álvarez-Coque et al. (2021)

Knowledge transfer, Technology transfer

Bakker et al. (2011)

Tho and Trang (2015)

Xie et al. (2016)

Osabutey and Jin (2016)

Bacon et al. (2019)

Trequattrini et al. (2019)

Poorkavoos et al. (2016)
Organizational

Organizational

Individual

Organizational

Individual

Territorial

Territorial

Organizational

Individual

Organizational

Territorial

Organizational

Individual

Project

Individual

Organizational

Organizational

Individual

Organizational

Organizational

Organizational

Organizational

Individual

Individual

Individual

Individual

Individuals

Organizational

Territorial

Project

Individual

Organizational

Individual

Organizational

Team

Organizational
Firm/public administration

Firm

University

University/research centre

Research centre

Firm*

Firm*

Firm

Societal

Firm

Firms/university*

Firm

Societal

Firm

Firm

Firm

Firm

Firm

Public administration

Public administration

Firm

University-firm

University

University

University

University

University

University

University-firm*

Firm

University-firm

Firm

University-firm- public admin

Firm-university

Firm

Firm

*in studies at territorial level, the sector indicates the main source of the data used for the study 
Table 6 Truth table considering PROJ (R\&D projects) as an outcome

\begin{tabular}{|ccccc|c|c|}
\hline QUAL & RDDPT & TECPROF & CONTAC & INFO & No. of cases & Cons \\
\hline$\circ$ & $\circ$ & $\circ$ & $\circ$ & $\circ$ & 2 & 0 \\
$\circ$ & $\circ$ & $\circ$ & $\bullet$ & $\circ$ & 1 & 0 \\
$\circ$ & $\circ$ & $\bullet$ & $\bullet$ & $\circ$ & 1 & 1.00 \\
$\circ$ & $\bullet$ & $\circ$ & $\circ$ & $\circ$ & 3 & 0 \\
$\circ$ & $\bullet$ & $\circ$ & $\bullet$ & $\circ$ & 2 & 0 \\
$\circ$ & $\bullet$ & $\bullet$ & $\circ$ & $\circ$ & 2 & 0 \\
$\bullet$ & $\circ$ & $\circ$ & $\circ$ & $\circ$ & 2 & 0 \\
$\bullet$ & $\circ$ & $\circ$ & $\bullet$ & $\circ$ & 9 & 0.01 \\
$\bullet$ & $\circ$ & $\bullet$ & $\circ$ & $\circ$ & 2 & 0 \\
$\bullet$ & $\circ$ & $\bullet$ & $\bullet$ & $\circ$ & 1 & 1.00 \\
$\bullet$ & $\bullet$ & $\circ$ & $\circ$ & $\circ$ & 3 & 0 \\
$\bullet$ & $\bullet$ & $\circ$ & $\bullet$ & $\circ$ & 2 & 0 \\
$\bullet$ & $\bullet$ & $\circ$ & $\bullet$ & $\bullet$ & 2 & 0.50 \\
$\bullet$ & $\bullet$ & $\bullet$ & $\bullet$ & $\circ$ & 2 & 0 \\
$\bullet$ & $\bullet$ & $\bullet$ & $\bullet$ & $\bullet$ & 6 & $\mathbf{0 . 8 3}$ \\
\hline
\end{tabular}

- presence of condition; $\bigcirc$ absence of condition

Table 7 Truth table considering SERV (service contracts) as an outcome

\begin{tabular}{|ccccc|c|c|}
\hline QUAL & RDDPT & TECPROF & CONTAC & INFO & No. of cases & Cons \\
\hline$\circ$ & $\circ$ & $\circ$ & $\circ$ & $\circ$ & 2 & 0 \\
$\circ$ & $\circ$ & $\circ$ & $\bullet$ & $\circ$ & 1 & 1.00 \\
$\circ$ & $\circ$ & $\bullet$ & $\bullet$ & $\circ$ & 1 & 1.00 \\
$\circ$ & $\bullet$ & $\circ$ & $\circ$ & $\circ$ & 3 & 0 \\
$\circ$ & $\bullet$ & $\circ$ & $\bullet$ & $\circ$ & 2 & 0 \\
$\circ$ & $\bullet$ & $\bullet$ & $\circ$ & $\circ$ & 2 & 0 \\
$\bullet$ & $\circ$ & $\circ$ & $\circ$ & $\circ$ & 2 & 0 \\
$\bullet$ & $\circ$ & $\circ$ & $\bullet$ & $\circ$ & 9 & 0.01 \\
$\bullet$ & $\circ$ & $\bullet$ & $\circ$ & $\circ$ & 2 & 0 \\
$\bullet$ & $\circ$ & $\bullet$ & $\bullet$ & $\circ$ & 1 & 0 \\
$\bullet$ & $\bullet$ & $\circ$ & $\circ$ & $\circ$ & 3 & 0 \\
$\bullet$ & $\bullet$ & $\circ$ & $\bullet$ & $\circ$ & 2 & 1.00 \\
$\bullet$ & $\bullet$ & $\circ$ & $\bullet$ & $\bullet$ & 2 & 0.50 \\
$\bullet$ & $\bullet$ & $\bullet$ & $\bullet$ & $\circ$ & 2 & 0 \\
$\bullet$ & $\bullet$ & $\bullet$ & $\bullet$ & $\bullet$ & 6 & $\mathbf{1 . 0 0}$ \\
\hline
\end{tabular}

- presence of condition; $\bigcirc$ absence of condition 
Table 8 Results for the analysis of sufficiency without PROJECTS and SERVICES

\begin{tabular}{|c|c|c|c|c|c|c|}
\hline \multirow{2}{*}{ Condition } & \multicolumn{3}{|c|}{ No PROJ } & \multicolumn{3}{|c|}{ No SERV } \\
\hline & 1 & 2 & 3 & 1 & 2 & 3 \\
\hline QUAL & & ○ & & & O & $\bullet$ \\
\hline RDDPT & & & • & & $\bullet$ & $\bullet$ \\
\hline TECPROF & & O & & & & \\
\hline CONTAC & 0 & & & O & & \\
\hline INFO & & & O & & & O \\
\hline Consistency & 0.46 & 0.26 & 0.43 & 0.50 & 0.25 & 0.18 \\
\hline Coverage & & & 1.00 & & & 1.00 \\
\hline Overall solution consistency & & & 0.68 & & & 0.68 \\
\hline Overall solution coverage & & & 1.00 & & & 1.00 \\
\hline
\end{tabular}

- presence of condition; $\bigcirc$ absence of condition

Acknowledgements The empirical study has been supported by the Social Council of the University of Cordoba. The article has benefitted from the grant reference CS02017-88354-R (INNOQUAL Project) funded by the Spanish National R\&D Scheme. The authors acknowledge the useful comments of two anonimous reviewers.

Open Access This article is licensed under a Creative Commons Attribution 4.0 International License, which permits use, sharing, adaptation, distribution and reproduction in any medium or format, as long as you give appropriate credit to the original author(s) and the source, provide a link to the Creative Commons licence, and indicate if changes were made. The images or other third party material in this article are included in the article's Creative Commons licence, unless indicated otherwise in a credit line to the material. If material is not included in the article's Creative Commons licence and your intended use is not permitted by statutory regulation or exceeds the permitted use, you will need to obtain permission directly from the copyright holder. To view a copy of this licence, visit http://creativecommons.org/licenses/by/4.0/.

\section{References}

Abbate, T., Cesaroni, F., Cinici, M. C., \& Villari, M. (2019). Business models for developing smart cities. A fuzzy set qualitative comparative analysis of an IoT platform. Technological Forecasting and Social Change, 142, 183-193

Adame-Sánchez, C., González-Cruz, T. F., \& Martínez-Fuentes, C. (2016). Do firms implement worklife balance policies to benefit their workers or themselves? Journal of Business Research, 69(11), 5519-5523

Álvarez-Coque, J. M. G., Mas-Verdú, F., \& Roig-Tierno, N. (2017). Technological innovation versus non-technological innovation: different conditions in different regional contexts? Quality \& Quantity, 51(5), 1955-1967

Arundel, A. (2017). Rethinking the effect of risk aversion on the benefits of service innovations in public administration agencies. Research Policy, 46(5), 900-910

Audretsch, D. B., Grimm, H., \& Wessner, C. W. (Eds.). (2004). Local heroes in the global village: Globalization and the new entrepreneurship policies (Vol. 7). Springer Science \& Business Media.

Aversa, P., Furnari, S., \& Haefliger, S. (2015). Business model configurations and performance: A qualitative comparative analysis in Formula One racing, 2005-2013. Industrial and Corporate Change, 24(3), 655-676

Bacon, E., Williams, M. D., \& Davies, G. H. (2019). Recipes for success: Conditions for knowledge transfer across open innovation ecosystems. International Journal of Information Management, 49, 377-387 
Bakker, R. M., Cambré, B., Korlaar, L., \& Raab, J. (2011). Managing the project learning paradox: A set-theoretic approach toward project knowledge transfer. International Journal of Project Management, 29(5), 494-503

Bennett, A., \& Elman, C. (2007). Case study methods in the international relations subfield. Comparative Political Studies, 40(2), 170-195

Benneworth, P. (Ed.). (2019). Universities and regional economic development. Routledge.

Berbegal-Mirabent, J., Ribeiro-Soriano, D. E., \& García, J. L. S. (2015). Can a magic recipe foster university spin-off creation? Journal of Business Research, 68(11), 2272-2278

Berger, E. S. (2016). Is qualitative comparative analysis an emerging method?-Structured literature review and bibliometric analysis of QCA applications in business and management research. In Complexity in entrepreneurship, innovation and technology research (pp. 287-308). Cham: Springer.

Borgman, C. (2015). Big Data, Little Data, No Data. Scholarship in the Networked World. Cambridge, MA: The MIT Press.

Bozeman, B., Fay, D., \& Slade, C. P. (2013). Research collaboration in universities and academic entrepreneurship: the-state-of-the-art. The Journal of Technology Transfer, 38(1), 1-67

Brown, R. (2016). Mission impossible? Entrepreneurial universities and peripheral regional innovation systems. Industry and Innovation, 23(2), 189-205

Buganza, T., Colombo, G., \& Landoni, P. (2014). Small and medium enterprises' collaborations with universities for new product development: An analysis of the different phases. Journal of Small Business and Enterprise Development, 21(1), 69-86

Cámara de Comercio de Córdoba. (2017). Actividades económicas. http://camaracordoba.com/es/serviciode-certificaciones/Como-ser-competitivo. Access 15 May 2021.

Cannaerts, N., Segers, J., \& Warsen, R. (2020). Ambidexterity and public organizations: A configurational perspective. Public Performance \& Management Review, 43(3), 688-712

Cheng, C. F., Chang, M. L., \& Li, C. S. (2013). Configural paths to successful product innovation. Journal of Business Research, 66(12), 2561-2573

Cobo-Benita, J. R., Rodríguez-Segura, E., Ortiz-Marcos, I., \& Ballesteros-Sánchez, L. (2016). Innovation projects performance: Analyzing the impact of organizational characteristics. Journal of Business Research, 69(4), 1357-1360

Coburn, C. E., Russell, J. L., Kaufman, J. H., \& Stein, M. K. (2012). Supporting sustainability: Teachers' advice networks and ambitious instructional reform. American Journal of Education, 119(1), 137-182

Cohen, W. M., \& Levinthal, D. A. (1990). Absorptive capacity: A new perspective on learning and innovation. Administrative Science Quarterly, 35(1), 128-152

Cooper, B., \& Glaesser, J. (2016). Exploring the robustness of set theoretic findings from a large n fsQCA: an illustration from the sociology of education. International Journal of Social Research Methodology, 19(4), 445-459

Copus, A., Skuras, D., \& Tsegenidi, K. (2008). Innovation and peripherality: An empirical comparative study of SMEs in six European Union member countries. Economic Geography, 84(1), 51-82

Corral de Zubielqui, G., Jones, J., Seet, P. S., \& Lindsay, N. (2015). Knowledge transfer between actors in the innovation system: a study of higher education institutions (HEIS) and SMES. Journal of Business \& Industrial Marketing, 30(3/4), 436-458

Curado, C., Muñoz-Pascual, L., \& Galende, J. (2018). Antecedents to innovation performance in SMEs: A mixed methods approach. Journal of Business Research, 89, 206-215

Dada, O., \& Fogg, H. (2016). Organizational learning, entrepreneurial orientation, and the role of university engagement in SMEs. International Small Business Journal, 34(1), 86-104

de Zubielqui, G. C., Lindsay, N., Lindsay, W., \& Jones, J. (2019). Knowledge quality, innovation and firm performance: a study of knowledge transfer in SMEs. Small Business Economics, 53(1), 145-164

Dusa, A. (2019). QCA with R. Springer International Publishing.

Edge, D. (1995). Reinventing the wheel. In S. Jasanoff, G. E. Markle, J. C. Petersen, \& T. Pinch (Eds.), Handbook of Science and Technology Studies. (pp. 3-23). Sage.

Fagerberg, J., Martin, B. R., \& Andersen, E. S. (Eds.). (2013). Innovation studies: evolution and future challenges. Oxford University Press.

Fan, D., Cui, L., Li, Y., \& Zhu, C. J. (2016). Localized learning by emerging multinational enterprises in developed host countries: A fuzzy-set analysis of Chinese foreign direct investment in Australia. International Business Review, 25(1), 187-203

Fan, D., Li, Y., \& Chen, L. (2017). Configuring innovative societies: The crossvergent role of cultural and institutional varieties. Technovation, 66, 43-56 
Fernández-Esquinas, M. (2020). Innovación: Una perspectiva sociológica. Revista Española de Sociología, 29 (3 - Sup1), 5-37. https://doi.org/10.22325/fes/res.2020.55.

Fernández-Esquinas, M., Pedraza Rodríguez, J. A., Muñoz Benito, R., \& Sánchez-Rodríguez, M. I. (2019). Relaciones universidad-empresa y transferencia de conocimiento: Un diagnóstico del sistema local de innovación. Consejo Social de la Universidad de Córdoba / UCO Press.

Fernández-Esquinas, M., \& Pinto, H. (2014). The Role of Universities in Urban Regeneration: Reframing the Analytical Approach. European Planning Studies, 22(7), 1462-1483

Fernández-Esquinas, M., Pinto, H., Pérez-Yruela, M., \& Santos-Pereira, T. (2016). Tracing the flows of knowledge transfer: Latent dimensions and determinants of university-industry interactions in peripheral innovation systems. Technological Forecasting and Social Change, 13, 266-279

Fiss, P. C., Marx, A., \& Cambré, B. (2013). Configurational theory and methods in organizational research, Research in the sociology of organizations, 38. Emerald.

Franklin, M. I. (2012). Understanding Research. Coping with the Quantitative-Qualitative Divide. Routledge.

Ganter, A., \& Hecker, A. (2014). Configurational paths to organizational innovation: qualitative comparative analyses of antecedents and contingencies. Journal of Business Research, 67(6), 1285-1292

García-Álvarez-Coque, J. M., Mas-Verdú, F., \& Roig-Tierno, N. (2021). Life below excellence: Exploring the links between top-ranked universities and regional competitiveness. Studies in Higher Education, 46(2), 369-384.

Gerrits, L., \& Verweij, S. (2018). The evaluation of complex infrastructure projects: A guide to qualitative comparative analysis. Edward Elgar Publishing.

Gherardini, A., \& Nucciotti, A. (2017). Yesterday's giants and invisible colleges of today. A study on the 'knowledge transfer' scientific domain. Scientometrics, 112(1), 255-271.

Glaesser, J., Gott, R., Roberts, R., \& Cooper, B. (2009). The roles of substantive and procedural understanding in open-ended science investigations: using fuzzy set qualitative comparative analysis to compare two different tasks. Research in Science Education, 39(4), 595

Guadix, J., Carrillo-Castrillo, J., Onieva, L., \& Navascues, J. (2016). Success variables in science and technology parks. Journal of Business Research, 69(11), 4870-4875

Gunawan, D. D., \& Huarng, K. H. (2015). Viral effects of social network and media on consumers' purchase intention. Journal of Business Research, 68(11), 2237-2241

Hall, P. A. (2003). Aligning ontology and methodology in comparative research. In J. Mahoney \& D. Rueschemeyer (Eds.), Comparative historical analysis in the social sciences. (pp. 373-404). Cambridge University Press.

Huggins, R., Johnston, A., \& Stride, C. (2012). Knowledge networks and universities: Locational and organisational aspects of knowledge transfer interactions. Entrepreneurship \& Regional Development, 24(7-8), 475-502

Kan, A. K. S., Adegbite, E., El Omari, S., \& Abdellatif, M. (2016). On the use of qualitative comparative analysis in management. Journal of Business Research, 69(4), 1458-1463

Khedhaouria, A., \& Thurik, R. (2017). Configurational conditions of national innovation capability: A fuzzy set analysis approach. Technological Forecasting and Social Change, 120, 48-58

Knorr Cetina, K. (1999). Epistemic Cultures: How the Sciences Make Knowledge. Harvard University Press.

Kraus, S., Burtscher, J., Niemand, T., Roig-Tierno, N., \& Syrjä, P. (2017). Configurational paths to social performance in SMEs: The interplay of innovation, sustainability, resources and achievement motivation. Sustainability, 9(10), 1828

Kraus, S., Ribeiro-Soriano, D., \& Schüssler, M. (2018). Fuzzy-set qualitative comparative analysis (fsQCA) in entrepreneurship and innovation research-the rise of a method. International Entrepreneurship and Management Journal, 14(1), 15-33

Kwiotkowska, A. (2018). Barriers to the development of spin-offs: a fuzzy-set-theoretic approach. Operations Research and Decisions, 28(4), 31-46

Leydesdorff, L. (1989). The relations between qualitative theory and scientometric methods in science and technology studies. Scientometrics, 15(5-6), 333-347

Liu, J., Wang, R., \& Xu, S. (2020). What academic mobility configurations contribute to high performance: an fsQCA analysis of CSC-funded visiting scholars. Scientometrics. https://doi.org/10. 1007/s11192-020-03783-0

Marcos-Marne, H. (2016). Autonomist and secessionist parties in post-communist democracies. Structural and institutional factors in the study of a dynamic phenomenon. National Identities, 18(4), 379-396.

Martin, B. R., Nightingale, P., \& Yegros-Yegros, A. (2012). Science and technology studies: Exploring the knowledge base. Research Policy, 41(7), 1182-1204 
Martin, R., \& Simmie, J. (2008). Path dependence and local innovation systems in city-regions. Innovation, Management Policy \& Practice, 10(2-3), 183-196

Mas-Verdú, F., Ribeiro-Soriano, D., \& Roig-Tierno, N. (2015). Firm survival: The role of incubators and business characteristics. Journal of Business Research, 68(4), 793-796

Meuer, J., Rupietta, C., \& Backes-Gellner, U. (2015). Layers of co-existing innovation systems. Research Policy, 44(4), 888-910

Mikalef, P., \& Pateli, A. (2017). Information technology-enabled dynamic capabilities and their indirect effect on competitive performance: Findings from PLS-SEM and fsQCA. Journal of Business Research, 70, 1-16

Moed, H. F., Glänzel, W., \& Schmoch, U. (2004). Handbook of Quantitative Science and Technology Research: The Use of Publication and Patent Statistics in Studies of $S$ \& T Systems. Springer.

Ordanini, A., \& Maglio, P. P. (2009). Market orientation, internal process, and external network: A qualitative comparative analysis of key decisional alternatives in the new service development. Decision Sciences, 40(3), 601-625

Ordanini, A., Parasuraman, A., \& Rubera, G. (2014). When the recipe is more important than the ingredients: A qualitative comparative analysis (QCA) of service innovation configurations. Journal of Service Research, 17(2), 134-149

Osabutey, E. L., \& Jin, Z. (2016). Factors influencing technology and knowledge transfer: Configurational recipes for Sub-Saharan Africa. Journal of Business Research, 69(11), 5390-5395

Ospina-Delgado, J., \& Zorio-Grima, A. (2016). Innovation at universities: A fuzzy-set approach for MOOC-intensiveness. Journal of Business Research, 69(4), 1325-1328

Padilla-Meléndez, A., Del Aguila-Obra, A. R., \& Lockett, N. (2013). Shifting sands: Regional perspectives on the role of social capital in supporting open innovation through knowledge transfer and exchange with small and medium-sized enterprises. International Small Business Journal, 31(3), 296-318

Pappas, I. O., Giannakos, M. N., Jaccheri, L., \& Sampson, D. G. (2017). Assessing student behavior in computer science education with an fsQCA approach: The role of gains and barriers. ACM Transactions on Computing Education (TOCE), 17(2), 1-23

Pappas, N. (2018). Hotel decision-making during multiple crises: A chaordic perspective. Tourism Management, 68, 450-464

Parida, V., Patel, P. C., Frishammar, J., \& Wincent, J. (2017). Managing the front-end phase of process innovation under conditions of high uncertainty. Quality \& Quantity, 51(5), 1983-2000

Paul, J., \& Criado, A. R. (2020). The art of writing literature reviews: what do we know and what do we need to know? International Business Review, 29(4), 101717.

Paul, J., Parthasarathy, S., \& Gupta, P. (2017). Exporting challenges of SMEs: A review and future research agenda. Journal of World Business, 52(3), 327-342

Paul, J., \& Rosado-Serrano, A. (2019). Gradual internationalization vs born-global/international new venture models. International Marketing Review, 36(6), 830-858

Perkmann, M., Tartari, V., McKelvey, M., Autio, E., Brostrom, A., D’Este, P., Fini, R., Geuna, A., Grimaldi, R., Hughes, A., Krabel, S., Kitson, M., Llerena, P., Lissoni, F., Salter, A., Sobrero, A.. (2013). Academic engagement and commercialization: A review of the literature on universityindustry relations. Research Policy, 42(2), 423-442

Pinto, H., Fernández-Esquinas, M., \& Uyarra, E. (2014). Universities and Knowledge Intensive Business Services (KIBS) as sources of knowledge for innovative firms in peripheral regions. Regional Studies, 49(11), 1873-1891

Plewa, C., Ho, J., Conduit, J., \& Karpen, I. O. (2016). Reputation in higher education: A fuzzy set analysis of resource configurations. Journal of Business Research, 69(8), 3087-3095

Poorkavoos, M., Duan, Y., Edwards, J. S., \& Ramanathan, R. (2016). Identifying the configurational paths to innovation in SMEs: A fuzzy-set qualitative comparative analysis. Journal of Business Research, 69(12), 5843-5854

Proksch, D., Haberstroh, M. M., \& Pinkwart, A. (2017). Increasing the national innovative capacity: Identifying the pathways to success using a comparative method. Technological Forecasting and Social Change, 116, 256-270

Ragin, C. (1987). The Comparative Method. University of California Press.

Ramos-Vielba, I., \& Fernández-Esquinas, M. (2012). Beneath the tip of the Iceberg. Exploring the Multiple Forms of University-Industry Linkages. Higher Education, 64, 237-265

Ramos-Vielba, I., Fernández-Esquinas, M., \& Espinosa-de-los-Monteros, E. (2009). Measuring university-industry collaboration in a regional innovation system. Scientometrics, 84(3), 649-667

Rasmussen, E., \& Borch, O. J. (2010). University capabilities in facilitating entrepreneurship: A longitudinal study of spin-off ventures at mid-range universities. Research Policy, 39(5), 602-612 
Rihoux, B., Álamos-Concha, P., Bol, D., Marx, A., \& Rezsöhazy, I. (2013). From niche to mainstream method? A comprehensive mapping of QCA applications in journal articles from 1984 to 2011. Political Research Quarterly, 66, 175-184

Rihoux, B., \& Marx, A. (2013). QCA, 25 Years after "The Comparative Method" Mapping, Challenges, and Innovations - Mini-Symposium. Political Research Quarterly, 66(1), 167-235

Rihoux, B., Rezsöhazy, I., \& Bol, D. (2011). Qualitative Comparative Analysis (QCA) in Public Policy Analysis: an Extensive Review. German Policy Studies, 7(3), 9-82

Roundy, P. T., Bradshaw, M., \& Brockman, B. K. (2018). The emergence of entrepreneurial ecosystems: A complex adaptive systems approach. Journal of Business Research, 86, 1-10

Ruiqi, W., Wang, F., Xu, L., \& Yuan, C. (2017). R\&D expenditures, ultimate ownership and future performance: Evidence from China. Journal of Business Research, 71, 47-54

Ryan, J. C., \& Berbegal-Mirabent, J. (2016). Motivational recipes and research performance: A fuzzy set analysis of the motivational profile of high performing research scientists. Journal of Business Research, 69(11), 5299-5304

Saka-Helmhout, A., Chappin, M., \& Vermeulen, P. (2019). Multiple paths to firm innovation in SubSaharan Africa: How informal institutions matter. Organization Studies, 41(11), 1551-1575.

Schneider, C. Q., \& Rohlfing, I. (2016). Case studies nested in fuzzy-set QCA on sufficiency: Formalizing case selection and causal inference. Sociological Methods \& Research, 45(3), 526-568

Schneider, C. Q., \& Wagemann, C. (2010). Standards of Good Practice in Qualitative Comparative Analysis (QCA) and Fuzzy Sets. Comparative Sociology, 9(3), 397-418

Schneider, C. Q., \& Wagemann, C. (2012). Set-Theoretic Methods for the Social Sciences: A Guide to Qualitative Comparative Analysis. Cambridge University Press.

Schulte, F. (2018). The More, The Better? Assessing the Scope of Regional Autonomy as a Key Condition for Ethnic Conflict Regulation. International Journal on Minority and Group Rights, 25(1), 84-111

Sim, M., Conduit, J., \& Plewa, C. (2018). Engagement within a service system: a fuzzy set analysis in a higher education setting. Journal of Service Management, 29(3), 422-442

Snyder, H. (2019). Literature review as a research methodology: and overview and guidelines. Journal of Business Research, 104, 333-339

Tho, N. D. (2017). Using Signals to Evaluate the Teaching Quality of MBA Faculty Members: fsQCA and SEM findings. Education \& Training, 59(3), 292-304

Tho, N. D., \& Trang, N. T. M. (2015). Can knowledge be transferred from business schools to business organizations through in-service training students? SEM and fsQCA findings. Journal of Business Research, 68(6), 1332-1340

Thomann, E., \& Maggetti, M. (2020). Designing research with Qualitative Comparative Analysis (QCA): Approaches. Challenges, and Tools, Sociological Methods \& Research, 49(2), 356-386

Thorpe, R., Holt, R., Macpherson, A., \& Pittaway, L. (2005). Using knowledge within small and mediumsized firms: a systematic review of the evidence. International Journal of Management Reviews, 7(4), 257-281

Trequattrini, R., Massaro, M., Lardo, A., \& Cuozzo, B. (2019). Knowledge transfer and managers turnover: Impact on team performance. Business Process Management Journal, 25(1), 69-83.

Tsai, W. (2000). Social capital, strategic relatedness and the formation of intraorganizational linkages. Strategic Management Journal, 21(9), 925-939

van Raan, A. F. J. (Ed.). (1988). Handbook of Quantitative Studies of Science and Technology. Elsevier.

Venturini, T., Jensen, P., \& Latour, B. (2015). Fill in the gap: A new alliance for social and natural sciences. Journal of Artificial Societies and Social Simulation, 18, 1-4

Verweij, S., \& Trell, E. M. (2019). Qualitative Comparative Analysis (QCA) in Spatial Planning Research and Related Disciplines: A Systematic Literature Review of Applications. Journal of Planning Literature, 34(3), 300-317

Wagemann, C., Buche, J., \& Siewert, M. B. (2016). QCA and business research: work in progress or research agenda? Journal of Business Research, 69, 2531-2540

Warren, J. (2017). "The way things get done around here..." Exploring spatial biographies, social policy and governance in the North East of England. International Journal of Sociology and Social Policy, 37(11-12), 655-666

Whitley, R. (2000). The Intellectual and Social Organization of the Sciences. Oxford University Press.

Woltmann, S. L. (2012). Synergy or separation mode: the relationship between the academic research and the knowledge-transfer activities of Korean academics. Scientometrics, 90(1), 177-200

Woltmann, S. L., \& Alkærsig, L. (2018). Tracing university-industry knowledge transfer through a text mining approach. Scientometrics, 117(1), 449-472 
Woodside, A. G., \& Baxter, R. (2013). Achieving accuracy, generalization-to-contexts, and complexity in theories of business-to-business decision processes. Industrial Marketing Management, 42(3), 382-393

Wright, M., Clarysse, B., Lockett, A., \& Knockaert, M. (2008). Mid-range universities' linkages with industry: Knowledge types and the role of intermediaries. Research Policy, 37(8), 1205-1223

Wyatt, S., \& Balmer, B. (2007). Home on the range. What and where is the middle in science and technology studies? Science, Technology, \& Human Values, 32(6), 619-626.

Wyatt, S., Milojević, S., Park, H., \& Leydesdorff, L. (2015). Quantitative and qualitative STS: The intellectual and practical contributions of scientometrics. Available at SSRN 2588336.

Xie, X., Fang, L., \& Zeng, S. (2016). Collaborative innovation network and knowledge transfer performance: A fsQCA approach. Journal of Business Research, 69(11), 5210-5215

Zahra, S. A., \& George, G. (2002). Absorptive capacity: A review, reconceptualization, and extension. Academy of Management Review, 27(2), 185-203 